\title{
Policies to Nationalize the Private Sector Labor Force in a Matching Model With Public Jobs and Quotas
}

\section{Olivier Durand-Lasserve}




\section{About KAPSARC}

The King Abdullah Petroleum Studies and Research Center (KAPSARC) is a non-profit global institution dedicated to independent research into energy economics, policy, technology and the environment across all types of energy. KAPSARC's mandate is to advance the understanding of energy challenges and opportunities facing the world today and tomorrow, through unbiased, independent, and high-caliber research for the benefit of society. KAPSARC is located in Riyadh, Saudi Arabia.

This publication is also available in Arabic.

\section{Legal Notice}

(c) Copyright 2021 King Abdullah Petroleum Studies and Research Center ("KAPSARC"). This Document (and any information, data or materials contained therein) (the "Document") shall not be used without the proper attribution to KAPSARC. The Document shall not be reproduced, in whole or in part, without the written permission of KAPSARC. KAPSARC makes no warranty, representation or undertaking whether expressed or implied, nor does it assume any legal liability, whether direct or indirect, or responsibility for the accuracy, completeness, or usefulness of any information that is contained in the Document. Nothing in the Document constitutes or shall be implied to constitute advice, recommendation or option. The views and opinions expressed in this publication are those of the authors and do not necessarily reflect the official views or position of KAPSARC. 


\section{Key Points}

This paper analyzes the nationalization policies of the private sector labor force in an economy employing a large proportion of expatriates and with a large government wage bill.

We assess the employment effect of using the fiscal proceeds of a domestic energy price reform to subsidize the labor of nationals in the private sector.

We use two alternative partial equilibrium models of the labor market: the first one has a market clearing wage, and the second one with matching and a representation of job search directed toward either the public or the private sector. The models are calibrated on Saudi Arabia.

Our simulations show that labor market frictions and the attractiveness of the public sector for employees give more wage rigidities and increase the impacts of labor subsidies on unemployment. We also stress that the quotas limit the beneficial effects of labor subsidies on the unemployment of nationals and may render expat levies detrimental.

We show that a domestic energy price reform, where parts of the fiscal proceeds are used for labor subsidies, can substantially reduce the unemployment of nationals. 


\section{Introduction}

G ulf Cooperation Council (GCC) countries aim to employ more of their nationals in the private sector to absorb the inflow of new entrants into the labor force. They have put in place workforce nationalization policies to revert two peculiar features of their labor markets: the preference of nationals for public sector careers, and the crowding out of nationals by expatriate workers in the private sector.

The labor force nationalization policies of GCC countries relied on quotas to limit the number of foreign workers, before extending to other measures, including administrative rules, financial incentives and productivity-enhancing policies. Insurance regimes have been introduced to compensate for less stable careers in the private sector than in the public sector. In addition, expatriate levies have been imposed on foreign workers.

More recently, negative payroll taxes or in-work benefits, which we bundle under the category 'labor subsidies,' have emerged in some countries and have been encouraged by experts and international organizations (World Bank 2018; Hertog 2017). These subsidies can reduce the gap between national and expatriate labor costs and make the private sector more attractive for job candidates. The subsidies, especially at a large scale, have a cost and need to be financed. Therefore, the debate shifts toward broader fiscal reforms, where subsidies are financed by the proceeds of fiscal measures that increase (reduce) other government income (expenditure). The measures discussed in this paper that are able to confer such proceeds are an increase in expatriate levies, a cut in public payrolls, or the reform of administered energy prices. However, there has been no quantification or modeling analysis of such labor policies in GCC countries.
This paper proposes an assessment of the employment effect of labor market reforms in Saudi Arabia. We show how subsidies interact with pre-existing foreign quotas and with the public sector wage bill. We use two partial equilibrium models calibrated on Saudi Arabia to illustrate the impacts of tightening quotas, expatriate levies, wage subsidies, and a reduction in both unemployment benefits and the public payroll. We also simulate policy packages with labor subsidies financed by alternative measures.

Policies that increase labor productivity are crucial for employment, but investigating them would require a specific analytical framework, which is beyond the objectives of this paper.

We base our assessment on two models, both of which include national and foreign workers. The first one, the benchmark, is a neoclassical model with a market-clearing wage and voluntary unemployment. This model, however, does not explicitly represent the key features of the labor market for nationals. These key features are the mismatch between job vacancies and candidates, and the high attractiveness of government jobs over private sector jobs. This is why we also use a search model with matching, where labor market frictions create unemployment, as in Pissarides (1998). The search model also represents interactions between the public and the private labor market, as in Gomes (2015).

The paper makes four contributions to the literature on labor market reforms in GCC countries. First, it proposes a stylized analytical framework to explain how policies influence unemployment in the presence of a large public sector, market frictions, and foreign worker quotas. Second, it shows how this type of stylized model can be calibrated for policy simulations. Third, it simulates the effects of labor policies that are simply proposed or 
discussed in the literature. The quantification shows consequences, sometimes unintended, of employment policies in Saudi Arabia. Last, the paper shows the importance of representing market frictions and the public sector. These aspects are often neglected in computable general equilibrium (CGE) assessments, which prioritize the sectoral granularity over a representation of relevant labor market adjustments.
The rest of the paper is organized as follows. Section 2 gives an overview of the Saudi labor market and reviews the implemented or proposed labor force nationalization policies. Section 3 presents the two alternative models of the labor market: the benchmark market-clearing wage model and the search model. We also explain the calibration of the models on Saudi Arabia. Section 4 presents the effects of various policies on unemployment and compares the results of the two models. Section 5 quantifies fiscal reforms, in particular energy price reforms that finance labor subsidies. Section 6 concludes the paper. 


\section{Low Employment of Nationals: The Case of Saudi Arabia}

\subsection{The struggle to absorb new labor market entrants}

The labor force participation rate of nationals in Saudi Arabia is low compared with other major economies (Figure 1, Panel A). The participation rate of women is still around half the world average. The low overall participation rate of Saudi nationals is offset by a large share of foreign workers (Figure 1, Panel B).

Figure 1. Labor force participation of Saudis is low, but is offset by foreign workers.

\section{Panel A: Labor participation rate ${ }^{\mathrm{a}}$ in selected economies (as \% of population over 15 years old, 2018)}

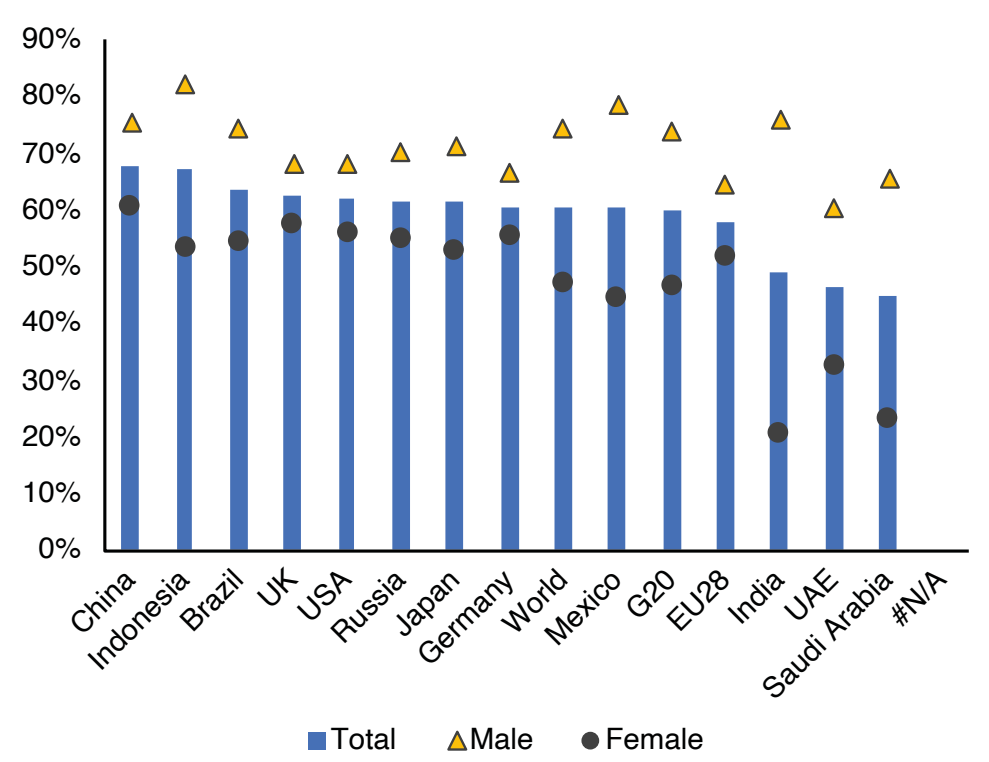

Panel B: Share of foreign-born workers (as \% of the labor force, 2018)

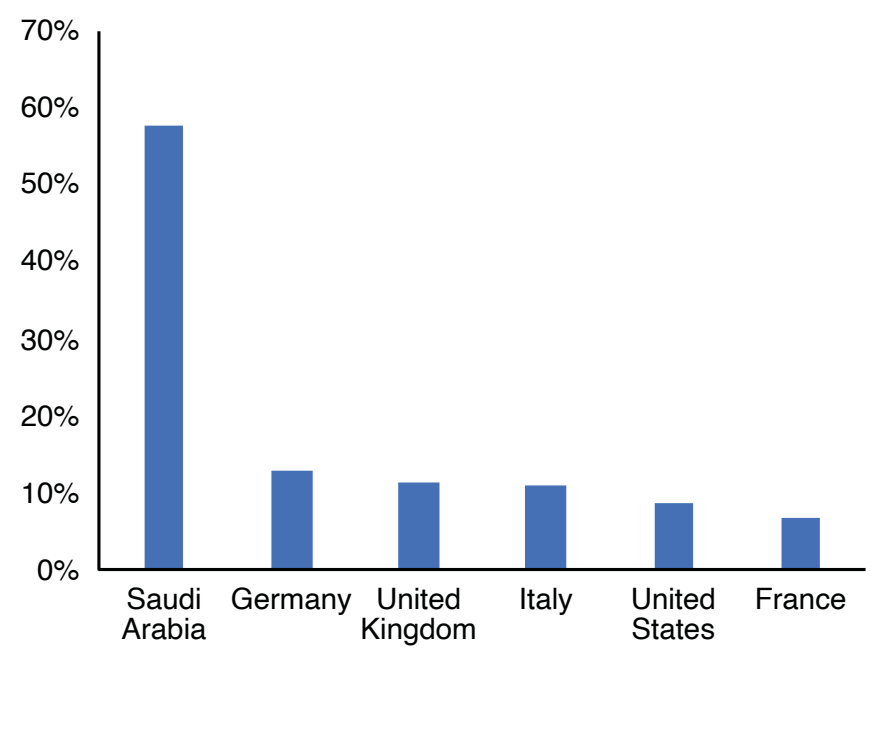

Sources: ILO Population and labor force modeled estimates (ILO 2020b), ILO Labor Migration statistics (ILO 2020a). For Saudi Arabia, GaStat Labor Force Survey of Q4 2019 (GaStat 2020). For the UAE: FCSA (2018). Note: ${ }^{2}$ the participation rate in Saudi Arabia is the participation rate of the nationals. In the other countries, it is the total participation rate of nationals and non-nationals.

Over the last decade, female labor force participation in Saudi Arabia has more than doubled (Figure 2, Panel A) and is well on track to meet the Saudi Vision 2030 objective of 30\% (Kingdom of Saudi Arabia 2017). Important legal reforms have improved women's access to employment and entrepreneurship (World Bank 2020). At the same time, the labor market struggles to absorb the inflow of new female participants. The jobs available in the labor market do not match the expectations of highly educated women. The unemployment rate of women is almost three times that of men (Figure 2, panel B). Unemployed women tend to be highly educated: two-thirds of them have at least a bachelor's degree, with half of this cohort having a specialization in educational sciences or humanities (Gastat 2020). 
Male unemployment is also high among nationals and above the world average (Figure 2, Panel B). Unemployment is particularly acute for the youth population, and the working age population growth may amplify this issue. The labor market will need to absorb an increase in the working age population ${ }^{1}$ of around $1.8 \%$ annually (GaStat 2019). At the same time, unemployment needs to drop to $7 \%$, from $12 \%$ in 2019 , to meet the Vision 2030 objective.

Figure 2. The participation rate has increased and unemployment remains high.

Panel A: Participation rate of Saudis by gender (as \% of Saudi population over 15 years old)

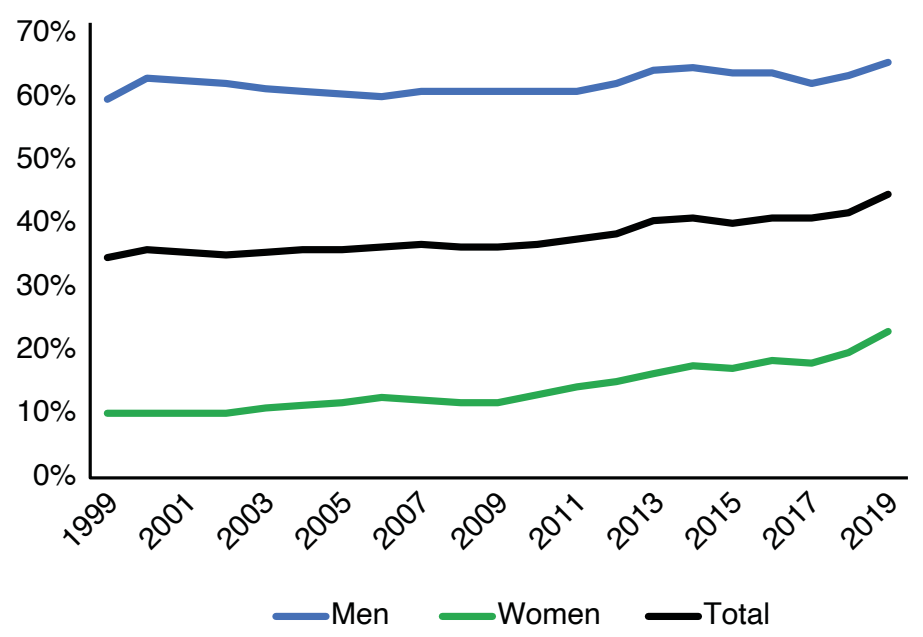

Panel B: Saudi unemployment by gender (as \% of the Saudi nationals in the labor force)

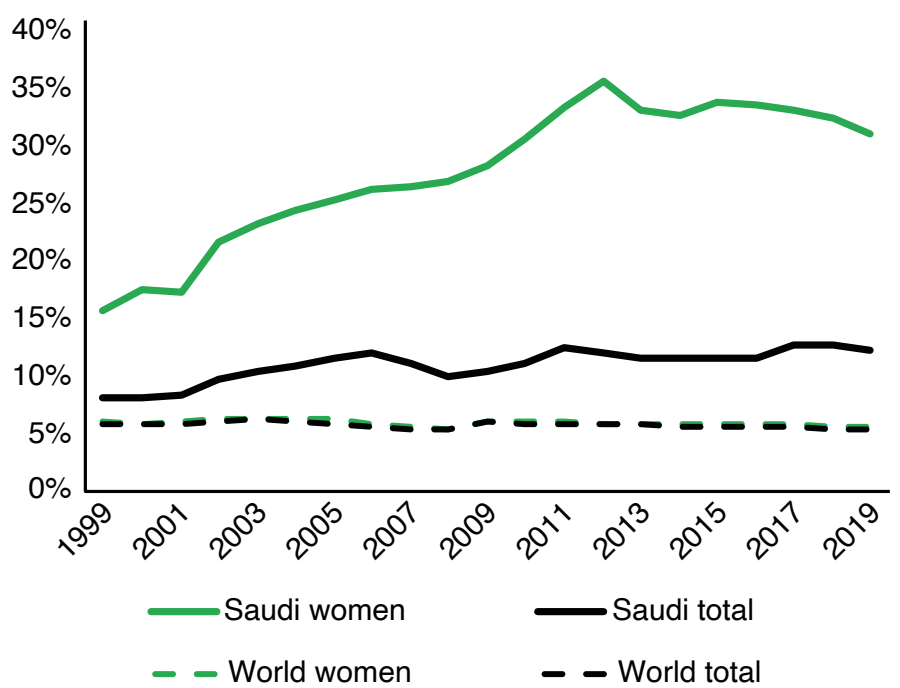

\subsection{Higher public sector wages and abundant foreign labor: the 'low private employment' trap}

The Saudi labor market is segmented along two lines. First, between the public and the private sectors, which offer different salaries and work conditions. Second, between nationals and expatriate workers, who are subject to different regulations.
Over $55 \%$ of the nationals registered in the social security system are employed in the public sector (Figure 3, panel A). The public sector is more attractive than the private sector thanks to higher wages (Figure 3, panel B), greater job security, social protection, and fewer working hours (EPoD 2015).

Foreign workers account for $80 \%$ of registered private sector jobs. ${ }^{2}$ They have very restricted access to government jobs, and they compete with nationals for private sector jobs, but the playing field is uneven. 
Employers have strong incentives to hire expats. Foreign workers' wages are lower (Figure 3, panel $B)$, because they are based on wage scales by nationality. In addition, numerous differences of employment status (in terms of hours, severance, contract duration) make foreign workers more competitive than nationals. Moreover, foreigners have legal residency status conditional upon having a job, and they cannot change their job without their employer's consent. This guarantees lower staff turnover, reduces foreigners' ability to negotiate their contracts, and maintains downward pressure on their wages. Last, unlike for nationals, there is no minimum wage for foreigners. ${ }^{3}$

Note that important reforms have recently been initiated to increase the mobility of foreign skilled workers. The Labor Reform Initiative (LRI), unveiled in November 2020, will "allow expatriate workers to transfer between employers upon the expiry of the binding work contract without the employer's consent" (MHRSD 2020).

Figure 3. The labor market segmentation lines: public versus private and Saudis versus foreigners.
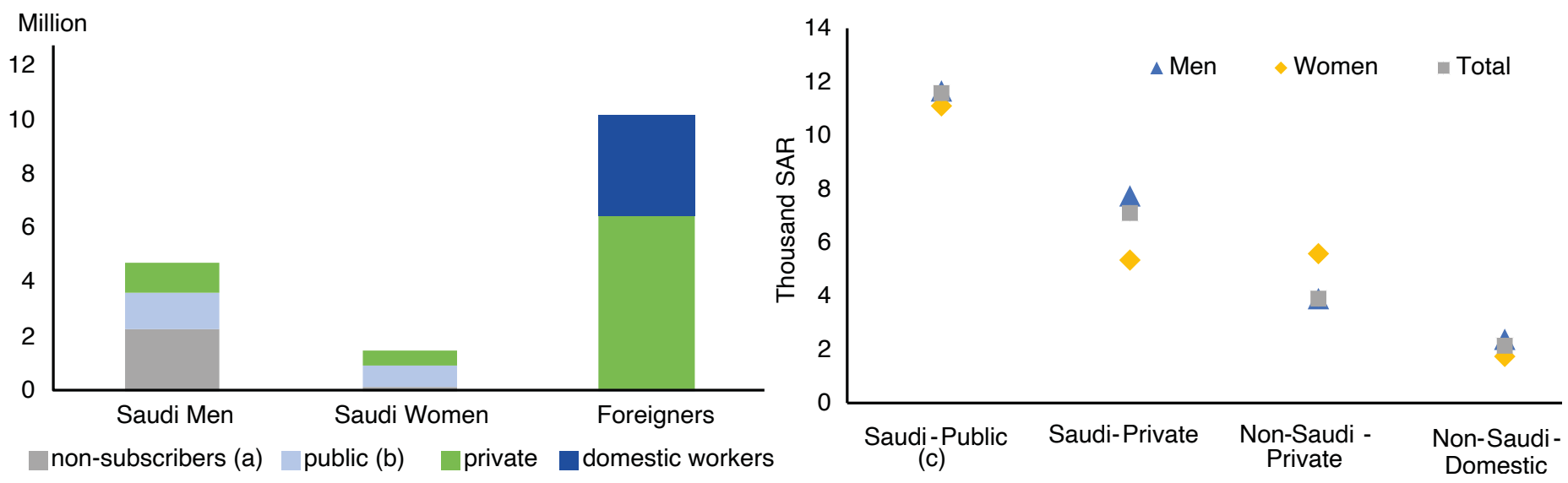

Sources: GaStat Labor Force Survey of Q4 2019 (GaStat 2020). Notes: a "non-subscribers" include those who are employed in the sense of ILO but whose job is not registered under a social insurance regime. These workers are not taken into account in the GaStat (2020) statistics' job categories. Non-subscribers include some independent workers, home workers, or family businesses. " The public sector includes "employees under the civil service social insurance system" and "government employees subject to insurance regulations" as defined in GaStat (2020). We also include here security and military personnel in the public sector, categories not included in the statistics of GaStat (2020). We estimate security and army personnel to be around 430,000, based on the available data on police figures in other middle east countries in UNODC (2018), and on the estimate of the size of armed forces given by IISS (2019). ${ }^{\circ}$ Excluding military and security personnel.

Middle East and Central Asia (MECA) countries have large public wage bills compared with their peers (Tamirisa and Duenwald 2018). Public sector employment may crowd out the private employment of nationals (Behar and Mok 2013). In Saudi Arabia, the abundant foreign labor force has suppressed wage and price inflation. This has contributed to maintaining high real incomes for nationals and developing price-competitive export industries, hence avoiding 'Dutch disease.' 
High public wages and a large expatriate labor force have created a double low private employment trap. Nationals have little incentive to work in the private sector, and private sector employers have little incentive to hire nationals absent of regulation.

Public sector employment started to slow after 2015 (Figure 4) as part of a budget consolidation effort amid very low international oil prices. But even though the opportunities in the public sector are shrinking, its persistent wage gap with the private sector still influences job seekers. The preference for public sector careers has also strongly influenced education choices, increasing the mismatch between the latter and the requirements of the private sector. Students and academic institutions have prioritized humanities and business administration curricula, which were the usual entry routes into public administration, and have dismissed scientific and engineering curricula. Women, for instance, have largely opted for studies in educational sciences. In $2010,74 \%$ of employed Saudi women were working in girls' schools (EPoD 2015).

Figure 4. Public sector employment has slowed, private employment has risen.

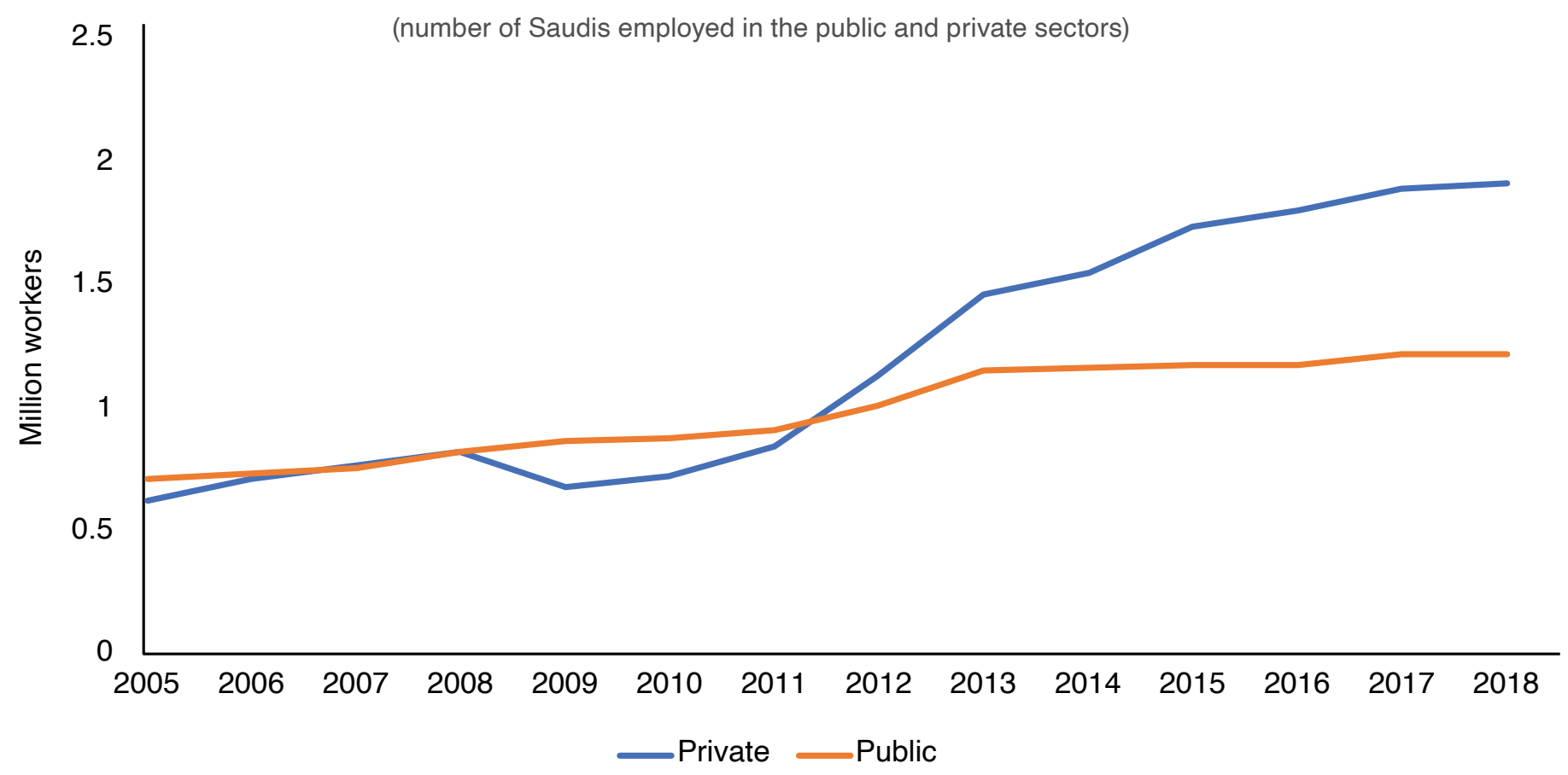

Source: SAMA (2019).

Note: Following the classification used in SAMA (2019) public jobs are those "under the civil service regulation" but excluding the jobs in the army and the security forces; the private jobs are the jobs "under the private insurance regulation." 


\section{Low Employment of Nationals: The Case of Saudi Arabia}

\subsection{Policies to foster the employment of nationals in the private sector}

Various policies have been put in place to increase the employment of nationals in the private sector. World Bank (2018) give an overview of the labor market reform agenda in GCC countries, and EPoD (2015) give a detailed analysis of Saudization policies. We can summarize the Saudization policies into three broad categories: administrative measures, productivity and mobility-enhancing policies, and decentralized market-based mechanisms. ${ }^{4}$

Administrative measures have been put in place to increase the proportion of national workers in various sectors of the economy. The most well-known of these policies - the Nitaqat program - was introduced in 2011 and has been updated since. Firms fall into various Nitaqat 'bands' depending on the proportion of national workers they employ. The Nitaqat band determines the ability of firms to obtain and renew work permits for foreign employees, and the share of national workers in a company's workforce needed for each Nitaqat band depends on the sector and the firm's size. There were originally four bands: platinum, green, yellow and red. Only firms in the red band faced hiring and work permit restrictions. In January 2020, the yellow band was placed under the same restrictions as the red band, making the Nitaqat system more constraining. Since its introduction, the Nitaqat has contributed to the growth of the employment of nationals in the private sector, as suggested in Figure 4.

Productivity and mobility-enhancing policies are 'growth' policies that aim to help nationals to develop the skills most demanded in the labor market and to lift barriers to activity or employment. There have been various educational efforts in this regard. Vocational training is an important element of Vision 2030 (Kingdom of Saudi Arabia 2017). Allowing women to drive has increased their mobility, and the large availability of subsidized housing has increased the mobility of workers across different regions of the Kingdom. The policies must also influence expectations about the job market to direct education and training choices toward the skills that the private sector needs.

Decentralized market-based policies reduce the wage gaps between the public and private sectors and between foreigners and nationals. Since 2017, firms have been required to pay fees on expatriate workers' dependents. These fees have increased in each subsequent year and serve to reduce the cost-competitiveness of foreign workers relative to that of nationals. In addition, the Human Resources Development Fund provides subsidies for first-time Saudi employees in the private sector for up to two years. The Employment Subsidy Program (ESP), introduced in 2019, is a system of in-work cash transfers for nationals employed in the private sector. This program covers 51,000 employees (Saudi Gazette 2020). These subsidies reduce the wage gap between the private and public sectors to attract nationals to private jobs. At the same time, they do not increase the cost of hiring nationals, and they improve nationals' competitiveness relative to foreigners. Some policies also tackle the non-wage gap between the private and public sectors. The Sanid program, introduced in 2014, is an insurance system that increases private sector workers' income security. It is complemented by assistance programs, such as Hafiz and Qarar, that aim to provide financial support to job seekers.

Administrative measures, such as quotas, can ensure that a given Saudization objective is 
achieved in a short period of time. However, they may have important side effects in terms of the quality of the jobs attained by nationals. The Nitaqat quotas have increased the proportion of nationals earning the minimum wage, suggesting that some of the jobs declared were not effective. This issue has particularly arisen in some sectors, such as construction (Hertog 2018). In addition, even though they have had a sizeable impact on the employment of nationals, the quotas represent a cost to firms. This has limited the growth and increased the exit rate of firms, in particular of those with a low initial proportion of nationals (Peck 2017). The Nitaqat system's parameters have been adjusted in several ways to mitigate side effects. Some Saudization objectives have been revised downward in some sectors. Such adjustments can help to avoid losing industrial competitiveness and reduce the upside pressure on inflation in the services sector. However, the elimination of the yellow band in January 2020 has eliminated a substantial amount of employer leeway. These adjustments to the Nitaqat system create human resource policy uncertainty, which is detrimental to employment.

When decentralized policies increase the cost of foreign labor, they may induce inflationary pressure and reduce price competitiveness. Certain adjustments have helped to mitigate these effects in certain industries (Gulf Business 2019). In addition, decentralized policies depend on the government budget and can be influenced by fiscal policy objectives and the business cycle. For instance, the levy on expatriates has been partially suspended as part of the fiscal response to the Covid-19 pandemic (Saudi Press Agency 2020). Decentralized measures may also be impacted by expenditure cuts. However, the government has demonstrated its commitment to funding the ESP during the pandemic in the context of overall expenditure cuts.

\subsection{Proposed fiscal reforms to finance labor subsidies for nationals in the private sector}

Several studies investigate fiscal reforms to boost nationals' employment and reduce wage gaps. Goyal and Fasano-Filho (2004) focus on market mechanisms that decrease the wage gap between nationals and foreigners in the private sector in GCC countries. They use a stylized equilibrium model with searching and matching. They emphasize that quotas on foreign labor may cause wage inflation and deter firms from hiring by increasing nationals' bargaining power. These outcomes may blunt the effects of such quotas on nationals' employment. Tamirisa and Duenwald (2018) advocate for public sector wage bill reductions to bridge the gap between the public and private sectors in the MECA region. They use a very stylized dynamic stochastic general equilibrium model with searching and matching calibrated on the Egyptian economy. They stress that public wage bill reduction policies decrease unemployment more efficiently when the reductions finance transfers to households rather than public investments.

Some studies support decentralized measures and propose financing the measures in a budget-neutral way by reducing the public sector wage bill or increasing administered energy prices. Hertog (2017) proposes labor market reforms for high-rent countries based on citizen revenues financed by hydrocarbon rents. This system can deliver better employment outcomes than the usual redistribution system based on public employment and administered prices can. He provides a very simple assessment of the necessary citizen revenues. 
Hertog (2018) focuses on Saudi Arabia and proposes subsidizing private sector employment through levies on expatriates and a reform of the sponsorship system. He also emphasizes that increasing the intersectoral mobility of expatriate workers can reduce the gap between their wages and nationals' wages. The LRI, which lifts barriers to foreign workers' mobility, is a key step in this direction. 


\section{Two Labor Market Models}

W e develop two partial equilibrium models of the labor market. In these models, nationals' private sector wages and employment are determined by the intersection between a labor demand curve and a wage curve. The effectiveness of labor cost reduction policies on unemployment depends on the shapes of the labor demand and the wage curves. The more labor demand responds to labor costs and the less the wage curve responds to unemployment, the more effective the labor cost policies are. We show below how having quotas for foreign workers reduces the responsiveness of labor demand to labor cost. We derive the wage curve for the competitive and the benchmark model, and we show how searching and the public sector job opportunities influence the relationship between wages and employment.

We use these models to assess how administrative measures, such as relaxing quotas, and market-based policies, such as employment subsidies, influence nationals' private sector wages and employment. We show that the quotas reduce the responsiveness of labor demand to labor costs. We also derive the wage curve for a benchmark competitive model. Using this wage curve, we demonstrate that searching and public sector job opportunities influence the relationship between wages and employment.

In these models, technological change and labor productivity are exogenous. Hence, these models do not represent productivity-enhancing policies. Policies that increase labor productivity are crucial for employment. However, they are beyond the scope of this study and must be analyzed in an intertemporal framework.

\subsection{Benchmark: the competitive model}

In our benchmark competitive model, labor is demanded by a representative firm. This firm maximizes profits by adjusting its employment of national and expatriate (foreign) workers given their relative costs and limits on the proportion of expatriate workers. Labor is supplied by a representative utility-maximizing household of nationals. Flexible wages for nationals clear the private labor market, and employment adjusts through the number of workers. The number of hours worked is exogenous. Employment in the public sector is also exogenous. Firms and unemployed workers face no searching costs or search frictions.

The representative private sector firm produces a composite good $y$ by employing national workers $n_{p}$, expatriate workers $n_{e}$ and capital $k$. For simplicity, we assume that the capital stock $\bar{k}$ is exogenous.

$$
\begin{aligned}
& y=F\left(\bar{k}, n_{p}, n_{e}\right) \equiv A\left[\alpha \bar{k}^{(\sigma-1) / \sigma}+\right. \\
& \left.(1-\alpha) l\left(n_{p}, n_{e}\right)^{(\sigma-1) / \sigma}\right]^{\sigma /(\sigma-1)}(1)
\end{aligned}
$$

where $\sigma \geq 0$ is the elasticity of substitution between capital and labor. $A>0$ and $0 \leq \alpha<1$ are total factor productivity and the value share parameter for capital, respectively. National and foreign labor are imperfect substitutes and are combined in an aggregate denoted by $l$.

$$
l\left(n_{p}, n_{e}\right)=\left[\phi n_{p}^{(\xi-1) / \xi}+(1-\phi) n_{e}^{(\xi-1) / \xi}\right]^{\xi /(\xi-1)}
$$




\section{Two Labor Market Models}

where $0 \leq \xi$ is the elasticity of substitution between national and expatriate workers. The parameter $\phi$ represents the labor productivity of nationals relative to expatriates.

We represent the Nitaqat Saudization policy by introducing an exogenous quota on the proportion of foreign workers that firms can employ.

$$
q n_{p} \geq n_{e}
$$

The quota $q$, is the maximum ratio of expatriate workers to national workers. In other words, the number of foreign workers cannot exceed $q$ times the number of national workers. Like the Nitaqat system, it sets a minimum percentage of national workers in private sector firms. ${ }^{5}$ Reducing $q$ increases the stringency of the quota policy. Importantly, this quota is relative rather than absolute, meaning that it does not limit the number of foreign workers in absolute terms. The firm can hire more foreign workers as long as the number of nationals hired increases in the same proportion.

The wages of expatriate workers are set exogenously, meaning that their labor supply is infinitely elastic. The firm's demand for national and foreign labor solves the following maximization problem:

$\max _{\left(n_{p}, n_{e}\right)}\left\{F\left(\bar{k}, n_{p}, n_{e}\right)-\left(w_{p}\left(1+t_{p}\right)+a_{p}\right) n_{p}-\right.$ $\left.\left(w_{e}\left(1+t_{e}\right)+a_{e}\right) n_{e} \mid q n_{p} \geq n_{e}(\lambda)\right\}$

where $w_{p}$ and $w_{e}$ are the net wages received by national and expatriate workers, respectively. The labor cost paid by the employer includes net wages and payroll taxes. Following Pissarides (1998), we represent payroll taxes with parameters that are proportional $\left(t_{p}, t_{e}\right)$ and not proportional $\left(a_{p}, a_{e}\right)$ to wages. The latter part may reflect labor subsidies for nationals $\left(a_{p} \leq 0\right)$ or levies on expatriate workers $\left(a_{e} \geq 0\right)$. The price of the composite good is the numeraire in the model. $\lambda$ is a nonnegative dual variable that is associated with the quota constraint.

The optimal demand for each type of labor is determined by setting its marginal productivity equal to its marginal cost, as follows:

$(1-\alpha) \phi A^{\frac{\sigma-1}{\sigma}}\left(\frac{y}{n_{p}}\right)^{\frac{1}{\sigma}}\left(\frac{l}{n_{p}}\right)^{\frac{1}{\xi}-\frac{1}{\sigma}}=w_{p}\left(1+t_{p}\right)+a_{p}-\lambda q$

$(1-\alpha)(1-\phi) A^{\frac{\sigma-1}{\sigma}}\left(\frac{y}{n_{e}}\right)^{\frac{1}{\sigma}}\left(\frac{l}{n_{e}}\right)^{\frac{1}{\xi}-\frac{1}{\sigma}}=w_{e}\left(1+t_{e}\right)+a_{e}+\lambda$

$w_{e}\left(1+t_{e}\right)+a_{e}+\lambda$

Here, national workers' marginal productivity equals their cost corrected by a rental element that represents an implicit subsidy $\lambda q$ on their labor (Equation 3). This element is relevant when the quota of foreign workers is binding, that is, when $\lambda>0$. This implicit subsidy corresponds to an implicit $\operatorname{tax} \lambda$ on expatriate labor in Equation 4.

If the quota is not binding (i.e., $q, n_{p}>n_{e}$ ), then $\lambda=0$, and the optimum ratio of expatriates to national workers is

$$
\frac{n_{e}}{n_{p}}=\left(\frac{1-\phi}{\phi}\right)^{\xi}\left(\frac{\mathrm{w}_{p}\left(1+t_{p}\right)+a_{p}}{w_{e}\left(1+t_{e}\right)+a_{e}}\right)^{\xi}
$$

Unsurprisingly, when national labor becomes more costly relative to expatriate labor, the proportion of expatriate workers increases. This proportion responds to the relative labor cost increase with elasticity $\xi$, which is the elasticity of substitution between national and expatriate labor.

If the wage to nationals continues to increase, however, the quota $q$ will eventually bind. Then, the ratio of expatriates to nationals will be limited. When 
the quota is binding, the dual variable $\lambda$ is strictly positive. Thus, because the model includes the quota, the demand curve for nationals' labor has two portions. In one portion, which we call the "wage competition" portion $\left(n_{p}>q, n_{e^{\prime}} \lambda=0\right)$, the quota is non-binding because nationals' and expatriates' wages are competitive. In the other portion, which we call the "binding quota" portion $\left(q_{n} n_{p}=n_{e}, \lambda>0\right)$, the cost of nationals' labor is high relative to that of expatriates. These portions are delineated by a threshold wage to nationals, denoted $w_{p}^{*}$.

$w_{p}^{\star}\left(1+t_{p}\right)+a_{p}=\left(w_{e}\left(1+t_{e}\right)+a_{e}\right) q^{1 / \xi} \frac{\phi}{1-\phi}$

This threshold increases with the cost of foreign labor because national labor is competitive without the quota at higher wages when expatriates' wages are higher. The threshold decreases as the quota becomes more stringent (i.e., when $q$ decreases). If the quota is very stringent (i.e., $\mathcal{q}$ is very low), then the threshold approaches zero. In this case, the labor demand curve includes only the binding quota portion. On the contrary, if the quota is very large, the labor demand curve includes only the wage competition portion. Policies that reduce taxes on national labor (i.e., $t_{p}$ or $a_{p}$ ) shift the labor demand curve up (Equation 2), reducing the binding quota portion of the curve (i.e., $w_{p}^{*}$ in Equation 6 increases). Policies that increase the cost of foreign workers' labor by increasing $a_{e}$ or $t_{e}$ have the same effect.

For the binding quota portion of the labor demand curve (i.e., when $q_{n} n_{p}=n_{e}$ and $\lambda>0$ ), we can combine Equations (3) and (4) to obtain the following labor demand curve:

$(1-\alpha)(l(1, q) A)^{\frac{\sigma-1}{\sigma}}\left(\frac{y}{n_{p}}\right)^{\frac{1}{\sigma}}=\widetilde{w}$

$\widetilde{w}=w_{p}\left(1+t_{p}\right)+a_{p}+q\left(w_{e}\left(1+t_{e}\right)+a_{e}\right)$
The binding quota portion of the labor demand curve, described by Equation (7), differs from the wage competition portion, represented by Equation (3), in two ways when $\lambda=0$. First, the marginal productivity of a national worker, shown on the left-hand side of Equation (7), is different. Specifically, it also accounts for the productivity $m(1, q)$ of the $q$ expatriate workers that can be hired under the quota when the quota binds. Thus, a new national worker increases production both directly and indirectly because the firm can now hire $q$ more foreign workers. Second, the labor cost $\tilde{w}$, which adjusts to the marginal productivity, differs when the quota binds. In this case, it includes the labor costs of both the additional national worker and the additional foreign workers who can be hired under the quota. Thus, the marginal labor cost comprises both the wages paid to the new national worker and those paid to the $q$ new foreign workers.

The impact of a change in the tax on labor depends on the steepness of the labor demand curve over the two portions. The two-regime labor demand curve is illustrated in Appendix A. If expatriate and national workers are substitutes $(\xi \geq 1)$, then the labor demand curve is steeper in the binding quota portion than in the wage competition portion when $\lambda=0$. This property also holds if expatriate and national workers are complements to some degree. As long as this property holds, policies reducing national workers' labor costs impact nationals' employment less positively when the quota binds. Moreover, tightening the quota may blunt the effects on employment of measures to reduce the relative cost of nationals' labor.

Additionally, if the quota binds, a tax on foreign labor, such as an expatriate levy, reduces the demand for national labor, an unintended negative consequence. This outcome arises because, 


\section{Two Labor Market Models}

when $q n_{p}=n_{e}$, national and expatriate workers eventually become strictly complementary. In other words, it is impossible to change one quantity without changing the other. Because of this complementarity, increasing the tax on foreign labor reduces demand for both foreign and national labor.

If the quota were expressed in absolute terms (e.g., $n_{e}<\bar{n}$, where $\bar{n}_{e}$ is the maximum number of foreign workers), the results would be somewhat different. Firms would not have the option of relaxing the constraint on the number of foreign workers by hiring additional national workers. Thus, the labor demand curve in the binding portion would be steeper than in our model, which uses a relative quota. Furthermore, the impacts of labor subsidy policies on nationals' employment would be even smaller with an absolute quota.

In our benchmark model, the wage curve is a labour supply curve that results from households' trade-off between leisure and consumption. Unemployment is voluntary and results from a representative household's utility maximization behavior. When we introduce the labor search model, however, we abandon this standard neoclassical representation of unemployment.

A representative national household chooses its consumption $c$ of the composite good and the proportion $u$ of its labor force that is unemployed. We use the utility function

$\mathcal{U}=\left[\gamma c^{\frac{\epsilon-1}{\epsilon}}+(1-\gamma) u^{\frac{\epsilon-1}{\epsilon}}\right]^{\frac{\epsilon}{\epsilon-1}}$

where $0 \leq \gamma<1$ is the scale parameter and $\epsilon \geq 0$ is the elasticity of substitution between consumption and leisure. We normalize the size of the household's labor force to one and obtain the relation
Here, $n_{p}$ and $\bar{n}_{g}$ are the proportions of households employed in the private and public sectors, respectively. The latter proportion is exogenous.

Unemployed workers receive compensation $b$. The wage $\bar{w}_{g}$ in the public sector in exogenous. Assuming that the household's members pool their revenue (Merz 1995), we obtain a single budget constraint:

$c=\bar{w}_{g} \bar{n}_{g}+w_{p} n_{p}+b u$

Thus, the supply $n_{p}^{s}$ of labor to the private sector solves

$$
\begin{aligned}
& \max _{n_{p}}\left\{\left[\gamma\left(w_{p} n_{p}+\bar{w}_{g} \bar{n}_{g}+\left(1-\bar{n}_{g}-n_{p}\right) b\right)^{\frac{\epsilon-1}{\epsilon}}+\right.\right. \\
& \left.\left.(1-\gamma)\left(1-\bar{n}_{g}-n_{p}\right)^{\frac{\epsilon-1}{\epsilon}}\right]^{\frac{\epsilon}{\epsilon-1}}\right\}
\end{aligned}
$$

We can determine the household's labor supply from the first-order condition

$$
\frac{n_{p}^{S} w_{p}+\bar{w}_{g} \bar{n}_{g}}{\left(1-n_{g}-n_{p}^{S}\right)}=\left[\left(\frac{\gamma}{1-\gamma}\right)^{\epsilon}\left(w_{p}-b\right)^{\epsilon}-b\right]
$$

We assume that the unemployment benefits correspond to a fixed replacement ratio $\rho$ with respect to the private sector wage (i.e., $b=\rho w_{p}$ ). We also define the ratio of the public sector wage to the private sector wage as $v=\bar{w}_{g} / w_{p}$, with $v \geq \rho$. This ratio is a policy parameter that the government sets based on the private sector's wage level. The curve describing nationals' supply of labor to the private sector is

$$
\begin{gathered}
n_{p}^{S}=1-\frac{1+\bar{n}_{g}(\Gamma+v)}{1+\Gamma}, \\
\Gamma=\left(\frac{\gamma}{1-\gamma}\right)^{\epsilon}(1-\rho)^{\epsilon} w_{p}^{\epsilon-1}-\rho
\end{gathered}
$$

$n_{p}+\bar{n}_{g}+u=1$ 
If the public sector wage premia $v$ is above the threshold $v\left(\bar{n}_{g}\right)=1-1 / \bar{n}_{g}$ and consumption and leisure are substitutes, then the labor supply curve bends upward. In other words, a wage increase stimulates the labor supply. The labor supply curve may also bend upward if consumption and labor are complementary to some extent. Additionally, the slope of the labor supply curve decreases with the number $\bar{n}_{g}$ of public sector jobs. It also decreases with the ratio $v$ of public sector wages to private sector wages. Thus, high wages or employment in the public sector reduce and can eventually revert the positive relationship between private labor subsidies and private employment.

In summary, our benchmark private labor market model problem has five variables $\left(n_{p}, n_{e}, w_{p}, y\right.$ and $\left.\lambda\right)$ and five equations. These equations include the three optimality conditions implied by the firms' profit maximization problem, defined in Equation (2). The final two equations are the production activity, defined in Equation (1), and the labor supply, defined in Equation (9).

\subsection{Search equilibrium model}

Next, we consider a model with labor market frictions. We represent these frictions by searching and matching, as in Pissarides (1998). Furthermore, following Gomes (2015), we assume that unemployed workers search for jobs in either the private or the public sector but not both. We define $u_{i}$ as the number of unemployed workers who search for a job in sector $i=p, g$. We normalize the labor force to one, and we obtain

$$
n_{p}+n_{g}+u_{p}+u_{g}=1
$$

Following Pissarides (1998), we apply a Cobb-Douglas matching function. This function represents the number of matches between unemployed workers $u_{i}$ and job vacancies $v_{i}$ posted by firms in sector $i$ in a period.

$$
m_{i}\left(u_{i}, v_{i}\right)=\mu_{i} u_{i}^{\eta_{i}} v_{i}^{1-\eta_{i}}, \quad i=p, g
$$

where the parameters $\mu \geq 0$ and $0 \leq \eta \leq 1$ are the matching efficiency and the matching elasticity, respectively.

A posted job vacancy is filled with probability $q_{i}=\frac{m_{i}\left(u_{i}, v_{i}\right)}{v i}=q_{i}\left(\theta_{i}\right)=\mu_{i} \theta_{i}^{-\eta_{i}}$. Here, $\theta_{i}=v_{i} / u_{i}$ is the tightness of sector $i$ 's labor market from the perspective of the hiring firm. If there are more vacancies $v_{i}$ or fewer unemployed workers $u_{i}$ it is more difficult for firms to hire (i.e., $\theta_{i}$ is greater). The probability that an unemployed worker obtains a job is $\frac{m\left(u_{i}, v_{i}\right)}{u_{i}}=\theta_{i} q_{i}\left(\theta_{i}\right)$.

The separation rate $s_{i}(i=p, g)$ is exogenous. The dynamics of nationals' employment in sector i are given by

$$
\Delta n_{i}=v_{i} q_{i}\left(\theta_{i}\right)-s_{i} n_{i}, \quad i=p, g
$$

In the steady state, $\Delta n_{i}=0$. We can identify a version of the Beveridge curve that is modified to be specific to the private and public sector job markets, as follows:

$$
\begin{aligned}
& u_{p}=\frac{s_{p}}{s_{p}+\mu_{p} \theta_{p}^{1-\eta_{g}}}\left(1-n_{g}-u_{g}\right) \\
& u_{g}=\frac{s_{g}}{s_{g}+\mu_{g} \theta_{g}^{1-\eta_{g}}}\left(1-n_{p}-u_{p}\right)
\end{aligned}
$$

The cost of posting a vacancy for one period is $c_{i}$, and this cost should be included in the labor cost. Given that it takes $1 / q i\left(\theta_{i}\right)$ periods on average for a firm to fill a vacancy, the average capitalized recruitment cost per worker is $\frac{\left(r+s_{i}\right) c_{i}}{q_{i}\left(\theta_{i}\right)}$. We add this cost to the firm's labor cost in the profit-maximization problem described in Equation (2). The result is a slightly modified version of the two-portion demand 


\section{Two Labor Market Models}

curve for nationals' labor. In the portion where quota does not bind, we have

$(1-\alpha) A_{p}^{\frac{\sigma-1}{\sigma}}\left(\frac{y_{p}}{n_{i}}\right)^{\frac{1}{\sigma}}=\left(1+t_{w}\right) w_{p}+a_{p}+\frac{\left(r+s_{p}\right) c_{p} \theta_{p}^{\eta_{p}}}{\mu_{p}}$

Searching costs increase with labor market tightness, leading to increased labor costs. Thus, the labor demand curve shifts downward when nationals' employment increases. The increasing labor market tightness necessarily results in some amount of unemployment at equilibrium.

The cutoff wage $w_{p}^{* *}$ to national workers in the model with searching solves

$w_{p}^{\star \star}\left(1+t_{p}\right)+a_{p}-\frac{(r+s) c_{p} \theta_{p}}{\mu_{p}}=\left(w_{e}\left(1+t_{e}\right)+\right.$

$\left.a_{e}\right) q^{1 / \xi} \frac{\phi}{1-\phi}$

This threshold wage accounts for labor market tightness, the quota, and the cost of foreign labor. If the market for nationals' labor is very tight even when wages are relatively low, nationals may not be competitive with foreigners without a quota. The greater hiring costs associated with a tight labor market erode national workers' competitiveness. The binding quota portion of the curve corresponds to

$(1-\alpha)(l(1, q) A)^{\frac{\sigma-1}{\sigma}}\left(\frac{y_{p}}{n_{p}}\right)^{\frac{1}{\sigma}}=\widehat{w}$

$\widehat{w}=w_{p}\left(1+t_{p}\right)+a_{p}+\frac{\left(r+s_{p}\right) c_{p} \theta_{p}}{\mu_{p}}+q\left(w_{e}\left(1+t_{e}\right)+a_{e}\right)$

We assume that a perfect capital market exists with real interest rate $r$. We consider the values (i.e., the sum of discounted net revenue flows) of being unemployed and employed, denoted $U$ and $E$, respectively.

$$
\begin{aligned}
& r U_{i}=b+\theta_{i} q_{i}\left(\theta_{i}\right)\left(E_{i}-U_{i}\right) \quad i=p, g \\
& r E_{i}=w_{i}+s_{i}\left(U-E_{i}\right) \quad i=p, g
\end{aligned}
$$

Equation (16) describes the expected value of being unemployed and searching for a job in sector $i$. Specifically, this value is the sum of the instantaneous unemployment benefit $b$ and a value upgrade associated with finding a job in sector $i$. An unemployed worker finds a job in sector $i$ with probability $\theta_{i} q_{i}\left(\theta_{i}\right)$. The expected value $E_{i}$ of employment in sector $i$ (Equation 17) is the sum of sector $i$ 's wage and a devaluation due to job loss. A job loss in sector $i$ occurs with probability $s_{i}$.

In equilibrium, job searching in the private sector must provide the same expected value as job searching in the public sector provides (Gomes 2015). Thus,

$\theta_{g} q_{g}\left(\theta_{g}\right)\left(E_{g}-U\right)=\theta_{p} q_{p}\left(\theta_{p}\right)\left(E_{p}-U\right)$

We use Equations (16) and (17) to substitute for $\left(E_{i}-U_{i}\right)$ in Equation (18) and establish a link between public and private wages. When the following relationship holds, unemployed workers are indifferent between searching in the public or private sector:

$$
w_{p}-b=\left(w_{g}-b\right)\left(\frac{r+s_{p}}{\mu_{p} \theta_{p}^{1-\eta_{p}}}+1\right) /\left(\frac{r+s_{g}}{\mu_{g} \theta_{g}^{1-\eta_{g}}}+1\right)
$$

This equation is particularly important because it links private and public sector wages, thereby creating rigidities on the private sector wage. It represents the pass-through of public sector wages to private sector wages and shows that it depends on labor tightness $\left(\theta_{p}\right.$ and $\left.\theta_{g}\right)$ in the two sectors. Specifically, the pass-through is lower when the private labor market is tighter (i.e., when $\theta_{p}$ is greater). Furthermore, we note that $1 /\left(\mu \theta^{1-\eta}\right)$ reflects the average length of unemployment. Thus, Equation (19) also indicates that for a given public sector wage, the private wage only varies if the unemployment length before finding a job in one sector changes. 
To illustrate that, we define the replacement ratio $\rho=b / w_{p}$ and the public wage gap $v=w_{g} / w_{p}$ as policy parameters. Then, we obtain the following relationship between labor market tightness in the private and public sectors:

$\left(\frac{r+s_{p}}{\mu_{p} \theta_{p}^{1-\eta_{p}}}+1\right)=(1-\rho) /(v-\rho)\left(\frac{r+s_{g}}{\mu_{g} \theta_{g}^{1-\eta_{g}}}+1\right)$

In this case, the length of a job search in the public sector determines the lengths of unemployment in the public and private sectors.

Next, we need a wage determination equation. Following Pissarides (1998), we assume that the private sector follows a Nash wage-bargaining process. In other words, the wage $w_{p}$ is set to maximize the following objective function (Pissarides 1998):

$\mathcal{S}=\left(E_{p}-U\right)^{\beta}\left(J_{p}-V_{p}\right)^{1-\beta}$

$J_{p}$ and $V_{p}$ are the value of hiring a worker and the value of posting a vacancy, respectively. Thus, $J_{p}-V_{p}$ is the firm's surplus from the wage bargaining process. Likewise, $E_{p}-U$ represents the private sector worker's surplus from this process. The parameter $\beta$ represents workers' bargaining power, that is, it determines the proportion of the total surplus that the worker receives.

The value $J_{p}$ of a new hire corresponds to the difference between the hire's productivity (noted $y$ ') and cost. It also includes the change in value due to separation and the reopening of a vacancy, which occurs with probability $s_{p}$.

$r J_{p}=y^{\prime}-s_{p}\left(J_{p}-V_{p}\right)$
A vacancy's value is defined as the difference between value of filling the vacancy and the cost of posting the vacancy.

$r V_{p}=-c_{p}+q_{p}\left(\theta_{p}\right)\left(J_{p}-V_{p}\right)$

The number of vacancies is increasing when $V_{P}>0$; thus, in equilibrium, $V_{p}=0$. The first-order condition for maximizing $S$ in Equation (21) along with some calculations described by Pissarides (1998) lead to the following private sector wage curve:

$$
w_{p}=\frac{\beta c_{p}}{(1-\beta)\left(1+t_{p}\right)(1-\rho)}\left(\frac{r+s_{p}}{\mu_{p}}+\theta_{p}^{1-\eta_{p}}\right) \theta_{p}^{\eta_{p}}
$$

Combining Equations (22) and (20), we obtain the following private sector wage curve that takes into account the public sector wage:

$$
w_{p}=\frac{\beta c_{p}}{(1-\beta)\left(1+t_{p}\right)(v-\rho)}\left(\frac{r+s_{g}}{\mu_{g} \theta_{g}^{1-\eta_{g}}}+1\right) \theta_{p}
$$

The private sector wage is increasing with the private sector labor market tightness index $\theta_{p}$. However, it decreases with public sector labor market tightness $\theta_{g}$. A tighter public sector labor market means that job seekers are more enticed by the private sector.

In summary, the equilibrium of the labor search model corresponds to a system with nine variables: $n_{p}, n_{e}, w_{p}, y, \lambda, \theta_{p^{\prime}}, \theta_{g^{\prime}}, u_{p}$ and $u_{g}$. The system also includes nine equations. The firms' profit maximization provides three first-order conditions. The modified Beveridge curves (Equations 11 and 12) and the equation for indifference between private and public sector job searches (Equation 19) are also included. Finally, the system includes the wage curve (Equation 22), production activity (Equation 1) and the identity given by Equation (10). 


\section{Two Labor Market Models}

\subsection{Model calibration}

We calibrate the benchmark and search models using data for Saudi Arabia in 2019. Data on workers by nationality in the public and private sectors are taken from the labor force bulletin for the fourth quarter of 2019 provided by GaStat (2020). However, the GaStat (2020) data do not include workers in the security and military sectors. We estimate military and security sector workers $(430,000)$ based on data from UNODC (2018) and IISS (2019) and include them in the public sector total. The labor force bulletin also excludes workers who are not listed in the registers of the General Organization for Social Insurance or the Ministry of Civil Service. We do not include non-registered Saudi workers in our calibration.

We take the average wages of nationals and expatriates in the private and public sectors from GaStat (2020). In particular, the benchmark annual wages of nationals in the private and public sectors are $\bar{w}_{p}=85,200$ and $\bar{w}=120,000$ Saudi riyals (SAR), respectively. ${ }^{6}$ For simplicity, we assume that labor is not taxed in the benchmark scenario.

We set the replacement ratio used for unemployment benefits, $\rho$, equal to 0.3 . This value is less than the value used in the Sanid legislation, which specifies 0.6 for the first three months of unemployment and 0.5 for the next nine months. We use a lower ratio to account for the cap $(7,500$ SAR per month) on Sanid payments and limitations in terms of entitlements and durations. ${ }^{7}$ Our replacement ratio is also in line with the fact that not all unemployed workers are entitled to Sanid payments. Many of them have never held a job and may only qualify for the Hafiz assistance programs, which provide lower payments. Others may be only entitled to transfers through citizen accounts, which are even lower than the Hafiz payments.
We calculate the benchmark non-oil non-government sector GDP for 2019 based on national accounting statistics from Gastat (2019). We also use preliminary assessments of the non-oil private sector's 2019 growth rate. We compute the value share of labor based on employment and wage data from the labor force bulletin provided by GaStat (2020). We assume that the rental rate of capital is $10 \%$.

In our simulations, we set $\sigma=0.8$. This value is close to one, reflecting a stable value share of labor and capital. However, we set it to less than one to reflect a slight complementarity between capital and labor. We set $\xi=1.5$, implying substitutability between national and expatriate workers. We also estimate an alternative case with $\xi=0.7$, which indicates complementarity; the results are provided in Appendix C. We set $\epsilon=1.2$, which corresponds to substitutability between labor and leisure. In an alternative simulation, however, we set $\epsilon=0.8$, representing complementarity. The results are provided in Appendix D.

GaStat's labor force bulletin (2020) reports that the ratio of foreign to national workers in the private sector is 3.8. We assume that the ratio corresponds to binding quotas on foreign workers. Thus, we set $q=3.8$ by default. If the quotas were not binding, calibrating $\phi$ would simply require solving Equation (5) for $\phi$ given the calibrated values of $\xi$ and the labor cost. However, for our calibration year, Equation (5) does not hold because the quotas are binding. Thus, to calculate $\phi$ using Equation (5), we use data from 2010, before the quotas were introduced. Then, using data from 2019, we obtain the benchmark value $\pi=7.5$ for the dual variable associated with the quotas. Thus, in 2019, the binding quotas implied an annual subsidy on the wages of nationals employed in the private sector (i.e., $\bar{\lambda} q$ ) of 28,000 SAR. This subsidy is equivalent to one-third of their wages. 
Next, to calibrate the search model, we need to assign values to the parameters $s_{p^{\prime}} s_{g^{\prime}} \mu_{p^{\prime}}, \mu_{g}, \eta_{p^{\prime}} \eta_{g}$ $\beta$ and $c_{p}$. We also need to assign baseline values to the variables $u_{p}, u_{g}, \theta_{p}$ and $\theta_{g}$. These variables have no statistical source; data on the portion of unemployed workers seeking public sector jobs or the number of vacancies are not available.

We calibrate the separation rate $s_{p}$ of nationals in the private sector based on a turnover calculation. Specifically, we divide the number of suspended private contracts by the number of workers and obtain $s_{p}=0.4$. We assume that the separation rate in the public sector is four times less, meaning that $S_{g}=0.1$. This factor of four is roughly in line with the factor of three used by Gomes (2015). However, we set our value slightly higher to reflect the very high turnover among nationals in the private sector.

Next, we calibrate the baseline numbers of unemployed workers seeking jobs in the private and public sectors. Although precise data are unavailable, we deduce these values based on other model parameters. We use Equations (11) and (12) to substitute for $\mu_{p} \theta_{p}^{1-\eta p}$ and $\mu_{g} \theta_{g}^{1-n g}$ in Equation (20). We obtain the following equation, which holds at the benchmark equilibrium:

$\frac{r+s_{p}}{s_{p}} \frac{u_{p}}{n_{p}}+1=\left(w_{p}-b\right) /\left(w_{g}-b\right) \quad\left(\frac{r+s_{g}}{s_{g}} \frac{u_{g}}{n_{g}}+1\right)$.

We set $s_{p}, s_{g}, r, n_{p}, n_{g}, w_{p}, w_{g}$ and $b$ equal to their baseline values. Thus, we obtain a system with two equations (Equations 24 and 10) and two unknowns $\left(u_{p}\right.$ and $\left.u_{g}\right)$. Solving this system, we obtain $u_{p}=$ 111,000 and $u_{g}=712,000$. Thus, our baseline model implies that around $85 \%$ of unemployed workers are seeking a job in the public sector. Using Equations (11) and (12), we obtain values for the expressions $\mu_{p} \theta_{p}^{l-\eta p}$ and $\mu_{g} \theta_{g}^{l-\eta g}$. The inverses of these values indicate that the duration of unemployment is two months for those searching in the private sector.
However, it is 3.5 years for those searching in the public sector. This considerable gap is because public jobs provide great advantages in terms of both stability and wages.

To calculate the benchmark labor tightness index $\theta$, we assume that the private sector vacancy duration is four months, in line with Pissarides (1998). We assume that the corresponding duration in the public sector is six months. Thus, the ratio of the public sector vacancy duration to the private sector vacancy duration is in line with Gomes (2015) (30 and 20 days, respectively). Because $\theta$ is the ratio of the vacancy duration $v / m(u, v)$ to the employment duration (i.e., $\frac{v}{u}=\theta=v / m(u, v) /(u / m(u, v)$ ), we obtain $\theta_{p}=1.85$ and $\theta_{g}=0.14$. The labor tightness index is much greater for the private sector than for the public sector. We set $\eta_{p}=0.5$ based on Pissarides (1998), and we assume that $\eta_{g}$ takes the same value. Finally, using the values of $\eta_{p}, \eta_{g}, \mu_{p} \theta_{p}^{l-\eta p}, \mu_{g} \theta_{g}^{l-\eta g}, \theta_{p}$ and $\theta_{g}$, we obtain $\mu_{p}=4.1$ and $\mu_{g}=0.74$.

Finally, we solve Equation (22), the wage equation, to calibrate the cost $c_{p}$ of a vacancy in the private sector at the baseline. We obtain $c_{p}=28$. Given the vacancy duration, the separation rate and the interest rate, we obtain an annualized hiring cost of 4,850 SAR for nationals in the private sector. This cost is $5.5 \%$ of the wage, which is greater than the value of $2 \%$ found by Pissarides (1998). This discrepancy is largely due to nationals' high turnover in the private sector. 


\section{Simulations of Alternative Employment Policies}

W e next use the benchmark competitive and labor search models to assess the consequences of policies to Saudize the private sector workforce. The results that we focus on are nationals' unemployment and their wages in the private sector. Note that the quotas bind in the baseline scenario. Thus, the simulations reflect the interactions of the various policies with the existing quotas.

\subsection{Policies to stimulate the hiring of national workers in the private sector}

Here, we consider policies that support the hiring of nationals instead of expatriates in the private sector. We compare the effect of tightening the quotas on expatriate workers (i.e., lowering $q$ ) with those of two decentralized measures. The first is a subsidy for national workers' employment (with $a_{p}<0$ ), and the second is an increase in the levy on expatriates (with $a_{e}>0$ ).

The responses to these policy shocks are similar for both the benchmark model and the search model (Figure 5). However, the search model yields greater variation in unemployment and less variation in wages. We observe this outcome because wages adjust less in the search model than in the benchmark model. This difference is driven by the search model's labor market frictions and because public wages influence private sector wages more strongly in the search model.

The public wage largely determines the private sector wage in the search model, making it fairly rigid. In fact, the difference between the two wages is only due to changes in the markets' respective labor market tightness indexes (Equation 19). The weaker adjustment of wages in the search model helps to strengthen these policies' impacts on employment. Conversely, in the benchmark model, private sector wages fully adjust to match labor demand and supply, and the public and private labor markets are disconnected. Thus, the labor supply curve in the benchmark model is more vertical than the wage curve is in the search model.

Focusing on specific policies, we find that tightening the quotas is more beneficial to nationals' employment in the search model (Figure 5, Panel A). As described previously, the labor market frictions and the public sector's influence on private sector wages in the search model mitigate the wage inflation induced by higher quotas. Thus, the policy's effect on employment is magnified.

This finding that the quota's impact is greater in the presence of labor market frictions argues against Goyal and Fasano-Filho (2004). They suggest that labor market frictions may erode the beneficial effect on nationals' employment of limiting the number of foreign workers. They argue that reducing the number of foreign workers may instead increase nationals' bargaining power in the wage-setting mechanism. In our framework, such an increase corresponds to an increase in the parameter $\beta$. Without this hypothetical increase in $\beta$, we show that search frictions and public employment can amplify the positive employment effect of tightening the expatriate quotas.

Additionally our simulations show that increasing the levy on expatriates increases nationals' unemployment (Figure 5, Panel B). This result may appear surprising. We might expect that increasing foreign workers' relative cost should induce the hiring of nationals as substitutes for foreign workers. However, the expatriate quotas are binding 
in the baseline scenario. Hence, the baseline scenario is on the portion of the labor demand curve where foreign and national workers are fully complementary. Consequently, increasing the cost of one type of labor decreases the demand for both types of labor. If the quotas are not binding (Figure B.1 in Appendix), however, a levy on expatriates increases nationals' employment. Nationals' wage competitiveness increases, and they are substituted for expatriates.

Moreover, when the quotas are binding, a subsidy for national labor has a blunt effect on employment (Figure 5, Panel C). This effect is larger if the quotas are not binding (Figure B.1 in Appendix). However, eliminating the quota system would greatly increase unemployment and, eventually, reduce wages owing to pressure from the low wages of foreign workers.

\subsection{Policies to increase the attractiveness of private sector jobs}

In this section, we explore policies that reduce unemployment benefits and that lower the attractiveness of public sector careers. We consider the impact of a change in the replacement ratio $\rho$ that reduces unemployment benefits $b$ (because $\left.b=\rho w_{p}\right)$. We also simulate the effects of reducing the public sector wage $\left(w_{g}\right)$ and of reducing public employment $\left(n_{g}\right)$. All of these policies are expected to create downward pressure on the private sector wage and, thus, increase private sector employment.

In both the benchmark model and the search model, lowering the replacement ratio slightly reduces employment (Figure 6, Panel A). However, the effect is weaker in the search model. In this model, the replacement ratio has a limited impact on wages, which instead depend strongly on public wages.
Reducing the public sector wage stimulates private sector employment by reducing the necessary wage to attract workers to the private sector (Figure 5, Panel B). In the benchmark model, a decrease in the public sector wage corresponds to a decrease in non-private labor revenue, shifting the labor supply curve downward (see Equation 9). In the search model, the lower public sector wage is directly passed through to the private sector (see Equation 19), stimulating private sector employment. This pass-through is smaller when the private sector labor market is tighter, as is the case when the quotas are binding. Hence, in the search model, the quotas soften the effect of the public sector wage on wages and employment in the private sector. In an alternative simulation with a non-binding quota (Figure B.2 in Appendix), the pass-through is greater. Thus, reducing public sector wages has a greater positive effect on employment.

The models do not suggest that private employment is immediately crowded out by public employment. A reduction in public sector employment is not sufficiently offset by new private sector jobs. Hence, unemployment increases when public employment falls (Figure 5, Panel C). Reducing public employment has a smaller effect on private employment in the search model, resulting in greater unemployment than in the benchmark model. In the search model, if the private sector labor market is tight, reducing government employment has a very limited effect on private sector wages. If the quotas were not binding, however, the pass-through would be greater. In that case, more rigid private sector wages would increase the responsiveness of private sector employment to a reduction in public sector jobs. With no quotas, overall employment would also respond less negatively (Figure B.2 in Appendix).

Our finding that public employment does not crowd out private employment does not necessarily contradict the empirical analysis of Behar and Mok 


\section{Simulations of Alternative Employment Policies}

(2013). We develop a partial equilibrium model of the labor market. Thus, our framework focuses on the labor market channel. We do not account for some channels of transmission between the public wage bill and private sector employment described by Behar and Mok (2013). For example, they consider public companies crowding out private companies in the product market or by directing people's educational choices toward public sector jobs. Moreover, we do not assess the potential benefits of redirecting some of the fiscal proceeds from reducing the government wage bill toward labor market policies. This impact is evaluated in section 5.2 .

Figure 5. Effects of the quota, labor subsidies and expatriate levies on unemployment and wages.

Panel A: Effect of the foreign worker quotas
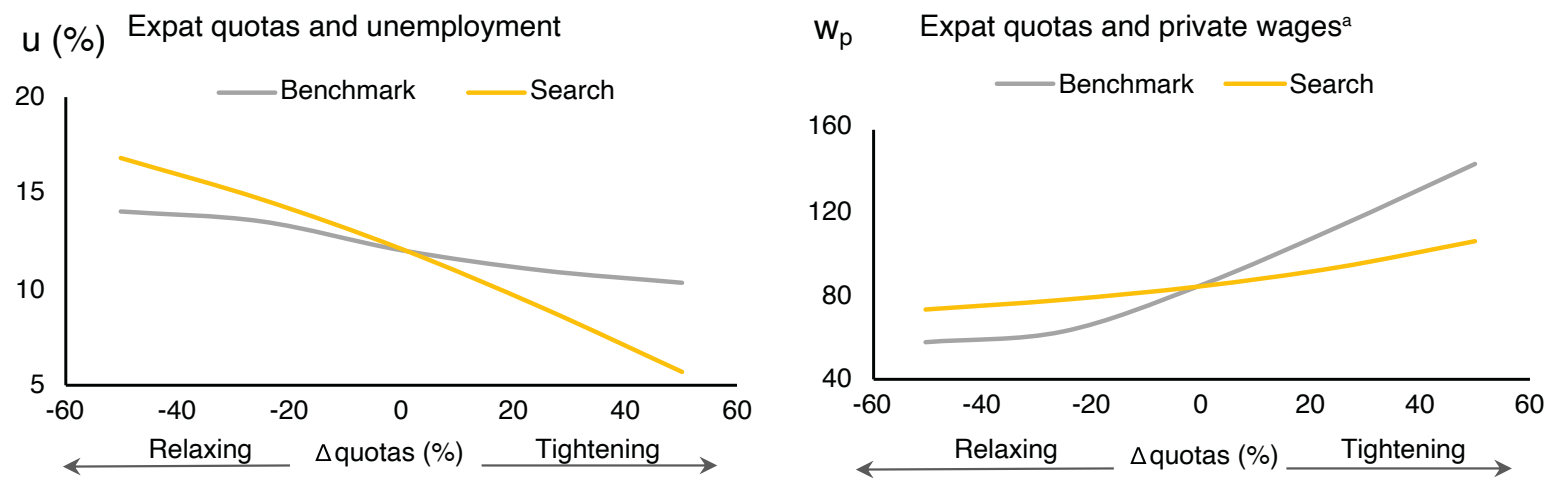

Panel B: Effect of expatriate levies
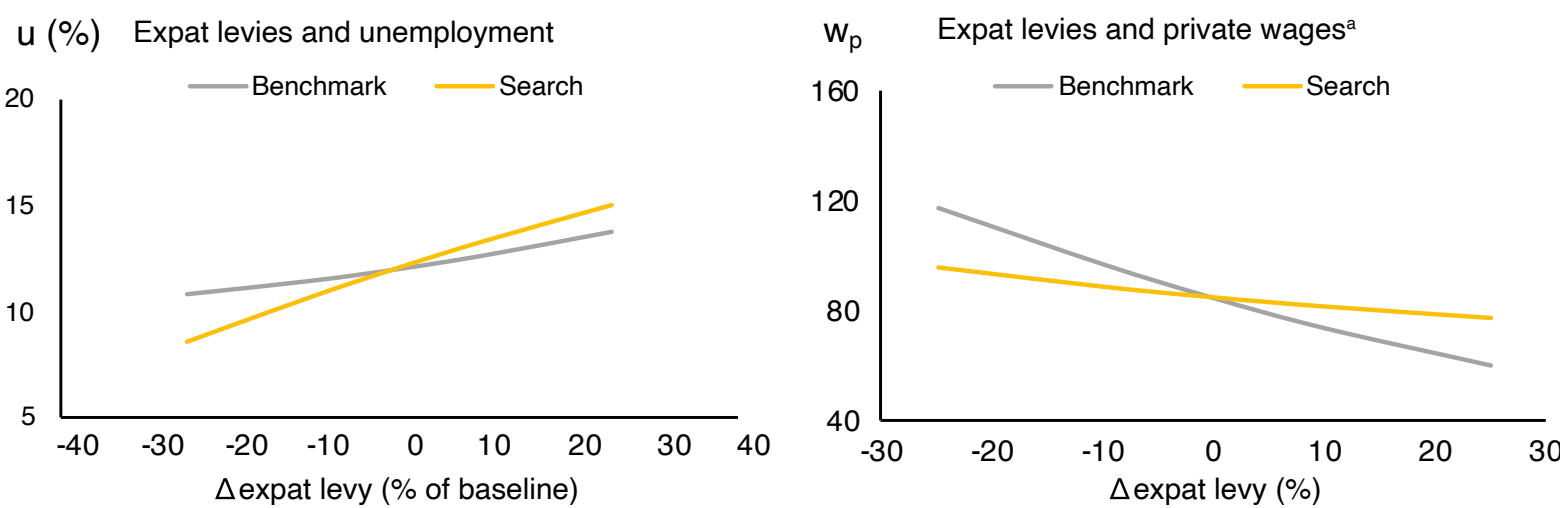

Panel C: Effect of subsidies on national labor
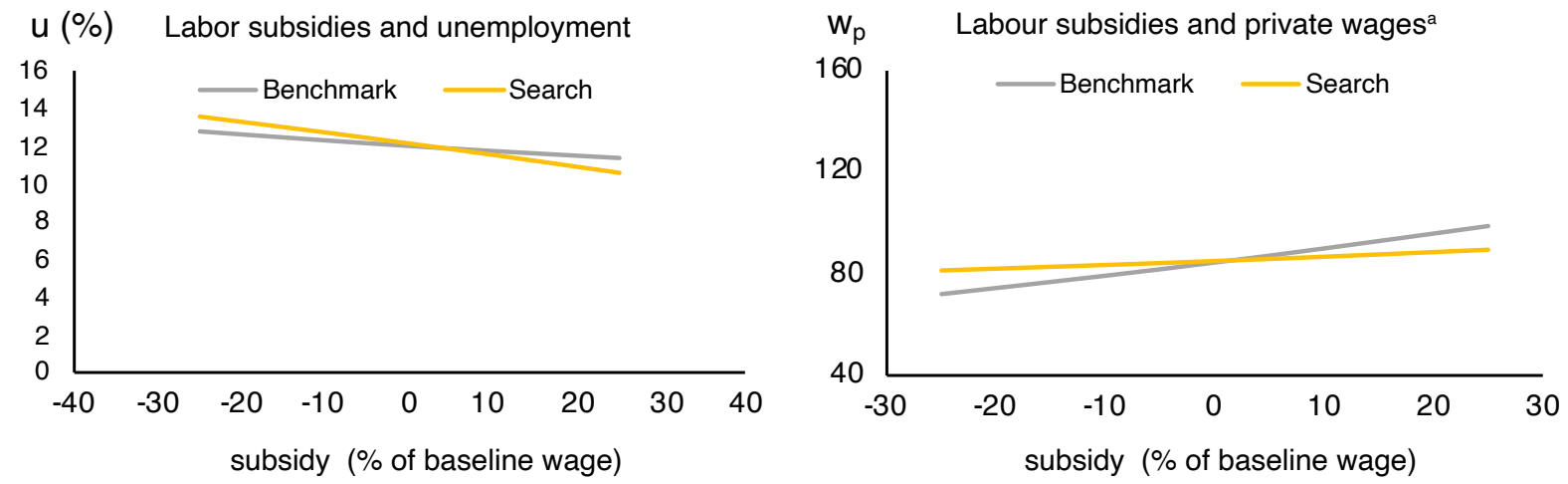

Note: a Nationals' private sector wages are in units of thousand SARs per year 
Figure 6. Effects of the replacement ratio and public sector wages and employment on unemployment and private sector wages.

Panel A: Effect of reducing the replacement ratio
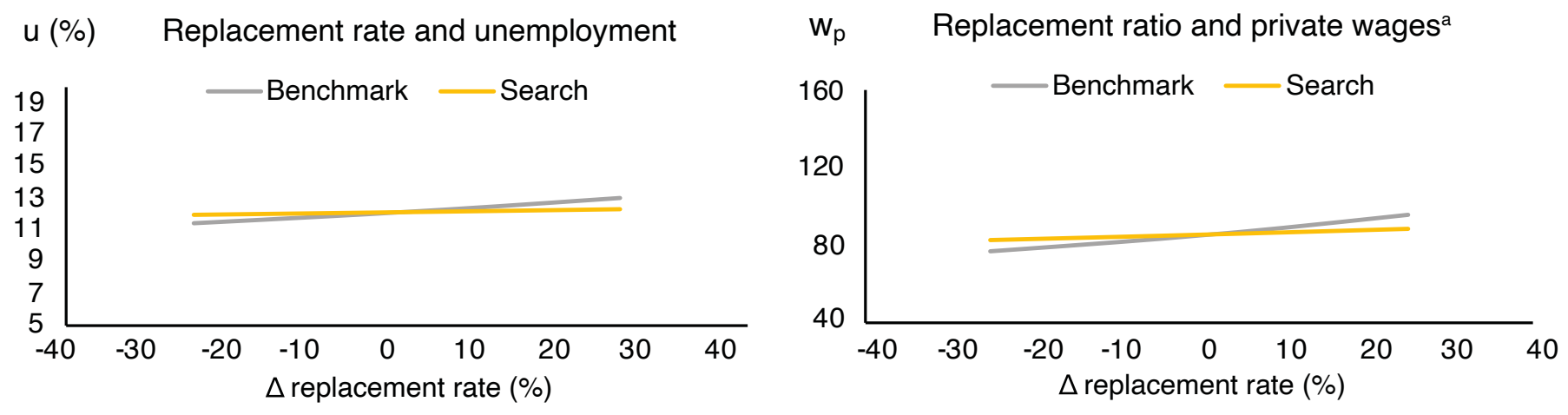

Panel B: Effect of reducing the public sector wage
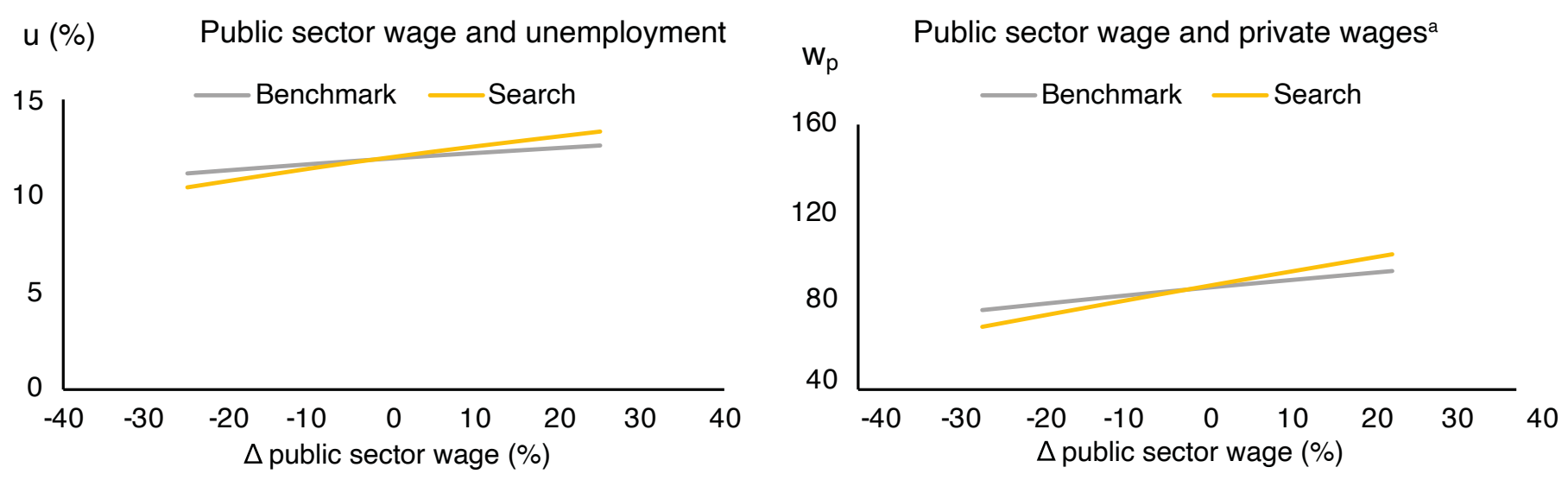

Panel C: Effect of reducing public sector employment

u (\%) Public employment and unemployment

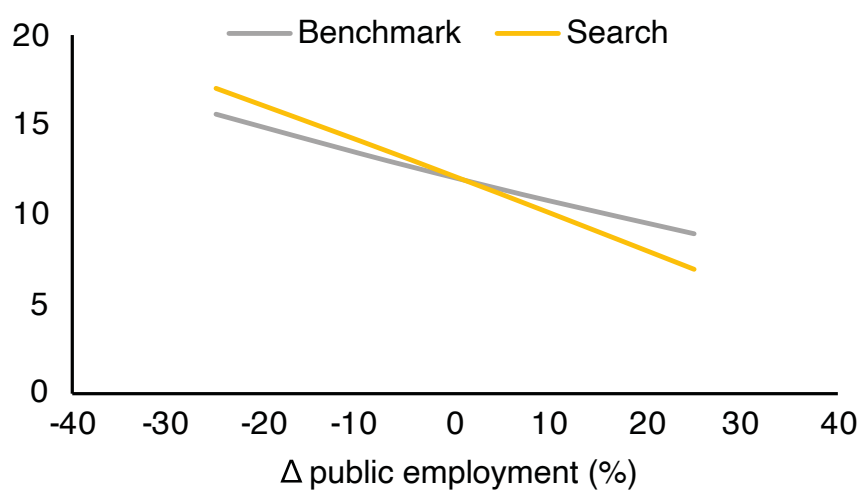

$\mathrm{w}_{\mathrm{p}} \quad$ Public employment and private wages $^{\mathrm{a}}$

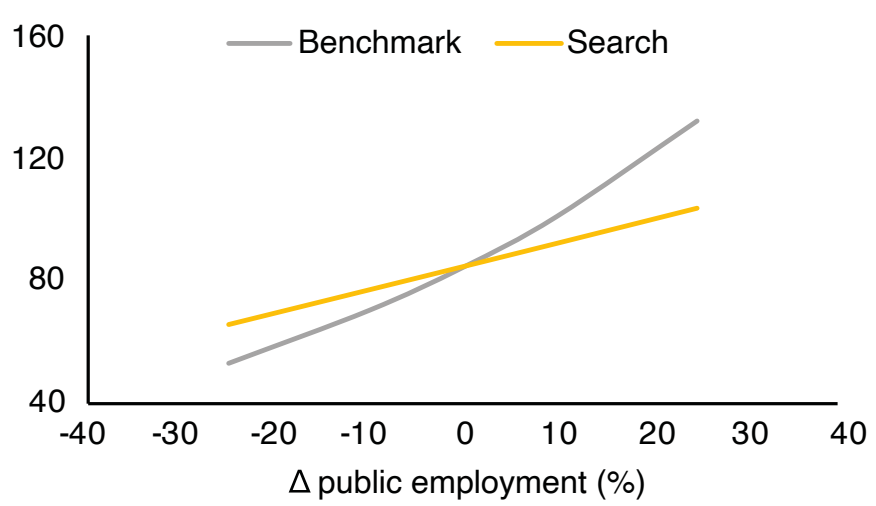

Note: a Nationals' private sector wages are in units of thousand SARs per year 


\section{Simulation of Budget-neutral Fiscal Reforms}

1 $\mathrm{n}$ this section, we assess a set of fiscal reforms. These reforms are policy packages in which a subsidy on nationals' labor is financed in a budget-neutral way by raising revenue from other sources or reducing expenditures. We first consider policies in which the expatriate levy is increased to finance the subsidy on nationals' labor in the spirit of Hertog (2018). Then, in line with Tamirisa and Duenwald (2018), we examine policies by which private labor subsidies are financed through a public wage bill reduction. Finally, we consider the effects of financing the subsidy with the proceeds from a domestic energy price reform, as Hertog (2017) proposes.

\subsection{Using the expatriate levy to finance labor subsidies}

Increasing the expatriate levy to finance subsidies on nationals' labor does not affect unemployment in our simulations unless the subsidy is extremely large (Figure 7, Panel A). As long as the quotas on foreign workers are binding, national and expatriate workers are strict complements. Firms employ national workers based on the aggregate labor cost, which is the average of the national and expatriate labor costs, as Equations (7) and (15) show. Increasing the tax on one type of labor to subsidize the other does not affect the average labor cost. Thus, it should not impact nationals' employment.

The subsidy is effective only when it is large enough that the quotas on foreign workers are no longer binding. In our simulation, this threshold is 30,000 SAR per year, implying that the subsidy is as high as $30 \%$ of the baseline wage. The implied levy on foreign workers is close to 8,000 SAR per year. To affect employment in a meaningful way, however, the subsidy and the levy must be even larger. Specifically, to reduce unemployment by one percentage point, the subsidy should be between 33,000 and 38,000 SAR. The levy therefore must be between 9,500 and 11,500 SAR (Figure 7, Panel B). Thus, when combined with a quota, a policy scheme in which a tax on foreign labor subsidizes national workers requires very large levies and subsidies. Hertog's (2018) proposal would create a massive fiscal shock in the context of binding quotas.

However, labor market frictions may increase the effectiveness of financing a subsidy with an expatriate levy. In the search model, in which the public sector's influence and labor market frictions create greater wage rigidity, this policy is more effective. Above the threshold of 30,000 SAR annually, employment adjusts much more in the search model than in the benchmark model as the subsidy increases.

\subsection{Reducing the government wage bill to finance labor subsidies}

Reducing public employment and using the savings to subsidize nationals' labor in the private sector may either increase or reduce unemployment. The drop in public sector employment enables the creation of private sector jobs. However, the number of new jobs may not fully offset the lost public sector jobs and increase total employment. The outcome depends on the size of the reduction in public employment (Figure 8, Panel A). For a small reduction in public employment, the marginal lost public sector job creates fewer than one private sector job, as Panel B of Figure 8 shows. When over $20 \%$ of public sector jobs are cut, however, private employment grows fast enough to increase total employment. This threshold corresponds to 
a 20,000 SAR annual subsidy to private labor. As public sector job cuts increase further, the number of private sector jobs created per public sector job cut increases, decreases, and then stabilizes above one. The ratio of created to lost jobs is higher in the search model. In this case, public sector job cuts reduce the attractiveness of searching for public sector jobs. This effect exerts downward pressure on the private sector wage curve, compounding the labor subsidy's positive effect on employment.
The reduction in public sector employment required to meaningfully impact nationals' unemployment is very large and seems highly unrealistic. Specifically, reducing nationals' unemployment rate by one percentage point requires cutting $60 \%$ of public sector jobs in the benchmark model. Even in the search model, $35 \%$ of public sector jobs would need to be cut. The annual labor subsidies in the two models are 50,000 SAR and 39,000 SAR, respectively. The numerous downsides of reducing public employment to this degree would certainly exceed the benefits in terms of total job creation.

Figure 7. Effects of labor subsidies financed by expatriate levies.

Panel A: Nationals' unemployment

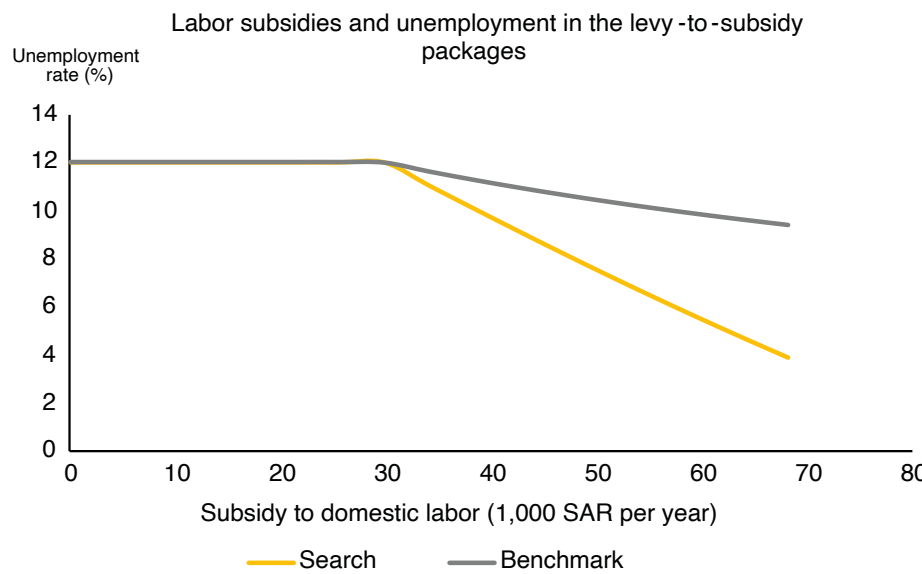

An alternative policy measure that may lower unemployment is reducing the public wage to finance the labor subsidy (Figure 9). A one percentage point reduction in unemployment could be achieved through a $10 \%$ reduction in public sector wages in the benchmark model. The corresponding wage reduction in the search model is $5 \%$. This policy is more impactful in the search model because the search model explicitly considers the public sector wage's influence on private sector job searches. Thus, the policy impacts both sides of the labor supply. The wage cuts that discourage workers from
Panel B: Implied increase in the expatriate levies

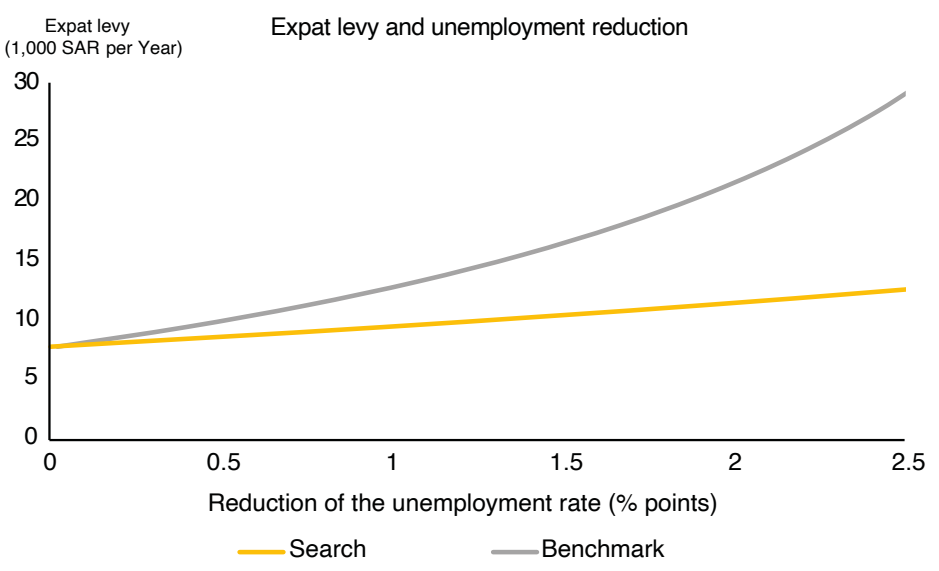

taking public sector jobs are mirrored by the subsidies that encourage them to take private sector jobs. As a result, the required subsidy is relatively modest compared with results of other simulations. An annual subsidy of 8,000 SAR (around $10 \%$ of wages) is sufficient to reduce unemployment by around $1 \%$ in the search model. Furthermore, cutting public sector wages by $20 \%$ and providing an annual subsidy of around 25,000 SAR makes the foreign worker quotas non-binding. Thus, the economy reaches the flatter portion of the demand curve, where subsidies have very large effects on unemployment. 


\section{Simulation of Budget-neutral Fiscal Reforms}

Figure 8. Effects of labor subsidies financed by public sector employment cuts.

Panel A: Nationals' unemployment

Response of nationals' total unemployment to a reduction Unemployment rate $(\%) \mathrm{h}$

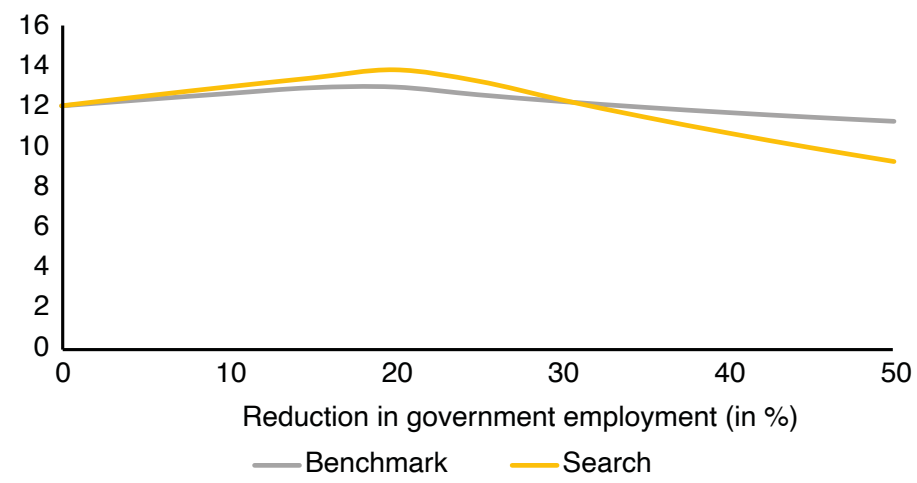

Panel B: Private sector jobs created per public sector job cut
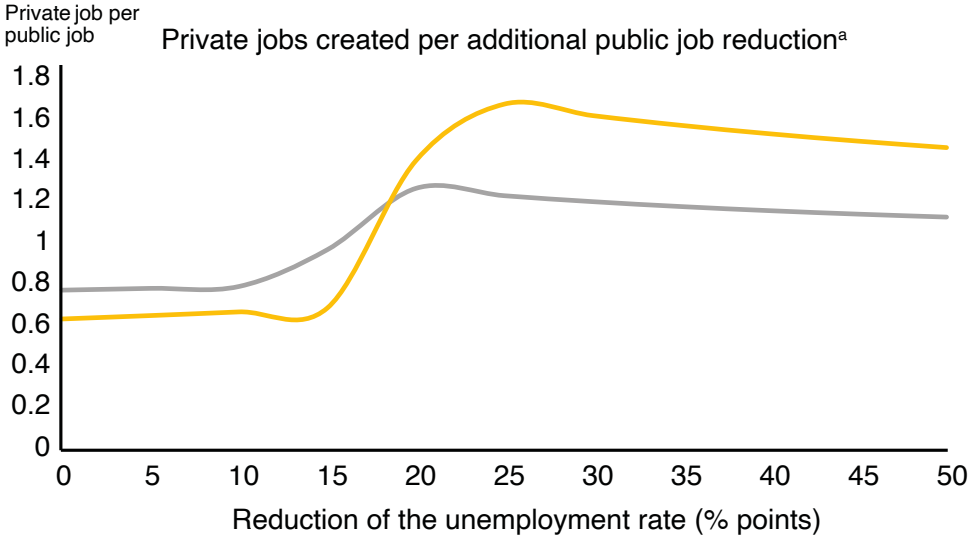

-Benchmark

_ Search

Note: ${ }^{a}$ Calculated as the marginal number of private sector jobs created divided by the marginal number of public sector jobs cut.

Figure 9. Effects of labor subsidies financed by a public wage reduction.

Panel A: Nationals' unemployment

Unemployment effects

$u(\%)$

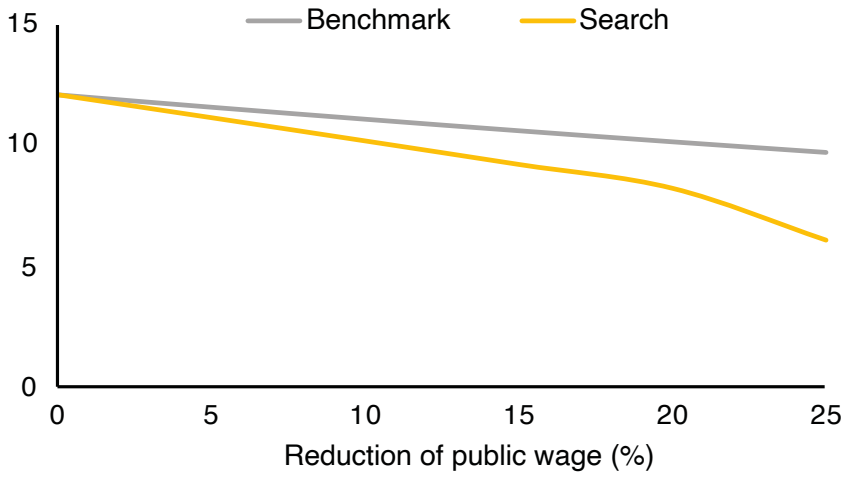

Panel B: Implied subsidy on national labor

Implied subsidy on national labor

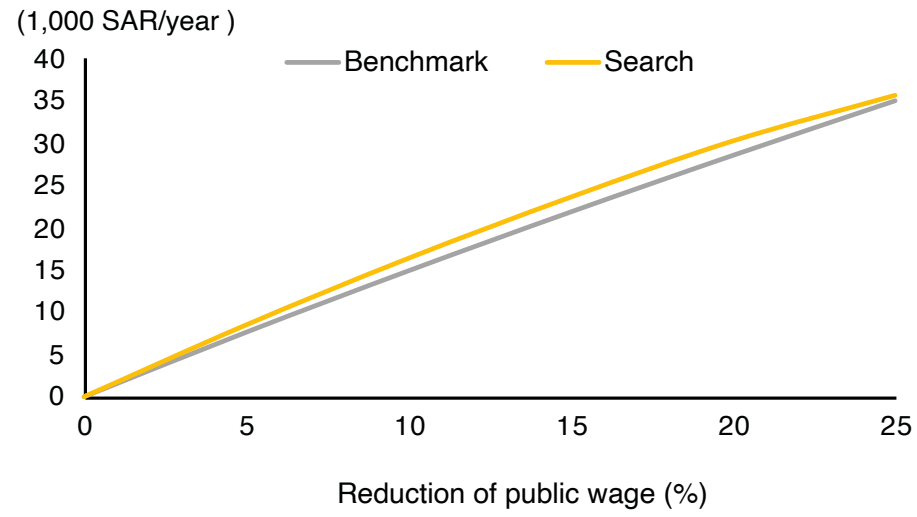




\subsection{Financing labor subsidies by reforming administered energy prices}

Deregulating energy prices is another means of financing subsidies on nationals' employment in the private sector. In Saudi Arabia, as in most MENA countries, energy and energy-intensive commodity prices are administered and are often set below market prices. This system burdens public finances because the government must cover the losses incurred by utilities pricing commodities below their costs of production. In addition, selling commodities at low domestic prices has a high opportunity cost, as they could otherwise be exported, generating high tax revenues. Saudi Arabia underwent waves of price reforms in 2016 and 2018. However, more reforms are still needed to achieve full price deregulation.

Prior studies have constructed models to assess the consequences of price deregulation on the energy system (Matar et al. 2015) and the broader macroeconomic consequences (Blazquez, Hunt, and Manzano 2017; Soummane, Ghersi, and Lefevre 2019; Durand-Lasserve et al. 2020). These studies propose various compensation mechanisms to mitigate the adverse effects of increasing domestic fuel prices on household incomes and industrial competitiveness. However, no studies have assessed the employment consequences of these policies, particularly in the case of the Saudization objectives.

Prior models of MENA countries stress the possible labor market effects of administered price reforms but do not explicitly represent unemployment or the labor supply. Hence, they offer little information about employment. In these models, policy shocks can alter wages and the allocation of labor across sectors if labor is mobile. Thus, these models can identify changes in aggregate wages, which provide an idea of whether labor income will increase or decrease following a policy shock. They can highlight the sectors in which unemployment may be positively or negatively affected by a reform. They can also identify which types of workers stand to win or lose from price reforms. However, they cannot determine the overall effect on total employment.

A few previous models are relevant in this context. First, Chemingui and Roe (2008) incorporate the effect of support for investment on nationals' employment in a model of Kuwait. They consider various types of labor by skill and nationality. However, they treat the labor supply of Kuwaiti nationals as exogenous. They assess unemployment based on changes in labor revenue. They translate labor revenue into numbers of jobs, assuming that each worker's number of hours worked, the wage rate and the participation rate remain constant. AIShehabi (2013) studies the labor market impacts of oil subsidy reforms in Iran. $\mathrm{He}$ finds that redistributing the fiscal proceeds to households reduces unemployment more than a redistribution program with increased investment does. He considers various types of labor and various sectors but does not consider the labor supply. Instead, he assumes that the labor supply is either perfectly elastic or perfectly inelastic. Shehabi (2020) takes the same approach to the labor market. She builds a CGE model of Kuwait and investigates how labor market reforms can magnify the effect of subsidy reforms. However, the labor supply is either perfectly elastic or perfectly inelastic in her model.

For this simulation, we use the results of the KAPSARC Energy Model - General Equilibrium developed by Durand-Lasserve et al. (2020). This model calculates the fiscal space created by an energy price reform, and we consider a reform that deregulates all domestic energy prices. Assuming that the international Arab Light oil price is around 


\section{Simulation of Budget-neutral Fiscal Reforms}

$\$ 70$, the fiscal proceeds from this reform are SAR 148 billion. We use our two partial equilibrium models to simulate the consequences of using some of these proceeds to finance employment policies.

A fiscal reform that combines energy price reforms and wage subsidies can sizably affect unemployment (Figure 10, Panel A). Redistributing just one quarter of the proceeds from the reform can reduce unemployment by one to two points. The employment effects are greater in the search model because of the wage rigidity inherent in this model.
Moreover, in the search model, less than $60 \%$ of the price reform's proceeds need to be reallocated to labor subsidies to make national workers competitive without quotas on foreign workers. The effect on unemployment is greater when the quotas are not binding.

Our results do not account for all the feedback effects of the employment policies that a general equilibrium model can assess. However, they clearly demonstrate that the framework for representing the labor market is crucial to determining the size of the employment effects.

Figure 10. Effects of labor subsidies financed by domestic energy price reforms.

Panel A: Nationals' unemployment

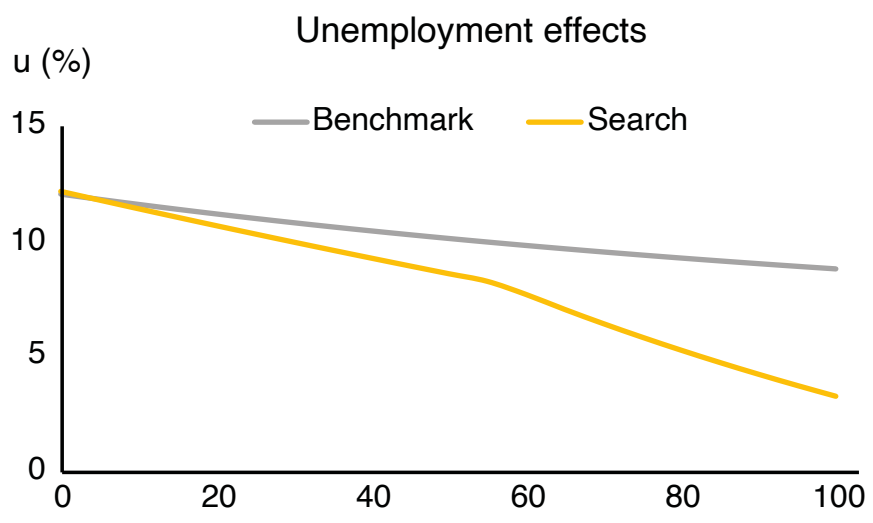

Share of price reform proceeds used for wage subsidies
Panel B: Implied subsidy on national labor

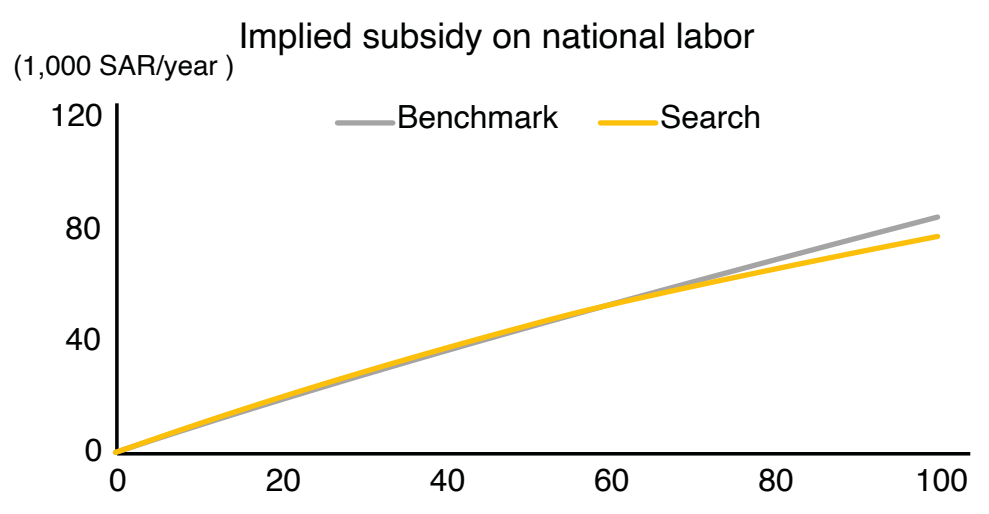

Share of price reform proceeds used for wage subsidies (\%) 


\section{Conclusion}

his study proposed a matching model that represents key features of a GCC economy's labor market. We incorporate the importance of foreign workers to the private sector, quotas on foreign workers and the attractiveness of public sector careers to nationals.

We calibrated the model to Saudi Arabia and simulated the impacts on unemployment of a wide variety of policies to nationalize the private workforce. We showed that subsidies on national labor are relatively inefficient for reducing unemployment when quotas are enforced, making expatriate levies counterproductive. Thus, fiscal reforms in which expatriate levies finance subsidies to national workers tend to be inefficient. If the quotas on foreign workers are binding, such reforms do not reduce labor costs. Only very high expatriate levies combined with subsidies on national labor can induce positive impacts on unemployment.

We also showed that reducing unemployment benefits has little influence on private sector wages or unemployment. This result is because private sector wages are largely influenced by public sector wages. We found no evidence that public employment directly crowds out private employment. However, reducing public sector wages increases private sector employment by exerting downward pressure on private sector wages.
Reducing the number of public jobs to finance labor subsidies would increase overall unemployment at first. Large public job cuts are necessary to trigger net positive impacts on unemployment. However, this policy may have other negative side effects that our models do not account for. Moderating public sector wages is therefore a more appropriate way to finance subsidies and to reduce unemployment. Finally, allocating just one quarter of the potential income from administered energy price reforms to labor subsidies would reduce nationals' unemployment by one to two points.

We performed our analysis in a partial equilibrium setting. Thus, it does not capture some of the revenue effects of reforms. In particular, it does not account for the influence of changes in household income on consumption. Furthermore, when we simulate policy schemes in which price reforms finance labor subsidies, we do not explicitly represent the feedback between energy prices and consumption. Incorporating the model in a CGE framework can provide a more detailed analysis of fiscal reforms and their effects on unemployment. This task is left for future work. However, this study shows that the specification of the labor market's functioning, which CGE models often overlook, is extremely important. Specifying a labor market with market-clearing wages in a CGE may reduce the results' relevance even if great efforts are dedicated to sectoral granularity. 


\section{Endnotes}

1 The population above 15 years old.

2 Excluding domestic workers. If we include domestic workers, the proportion of foreigners in the private sector is even higher.

3 There is no legal minimum wage in Saudi Arabia. But wages need to be above 3,000 SAR per month (US\$800) for workers to be included in the Saudization quotas system (the Nitaqat, see later). Hence in practice, this can be regarded as the minimum wage for Saudis.

4 These categories are very close to those of Goyal and Fasano-Filho (2004).

5 For simplicity, we formulate the Nitaqat system in terms of the ratio of foreign to national workers. However, formulating it in terms of the minimum share of Saudi workers, as in the Nitaqat system, is equivalent. In our notation, this share (i.e., $n_{p} /\left(n_{p}+n_{e}\right)$ ) must be greater than or equal to $1 /(1+q)$. Note that this share is an aggregated and simplified representation of the minimum proportion of Saudi workers given by the Nitaqat green band.

6 The currency peg is fixed at 1 USD $=3.75$ SAR.

7 Sanid is an insurance mechanism that is conditional on previous contributions. Sanid replaces $60 \%$ of a worker's salary during the first three months of unemployment, $50 \%$ during the following nine months (ILO 2015), and nothing after that. However, these payments are made only up to a given cap. The Hafiz system provides assistance for up to two years. 


\section{References}

AIShehabi, Omar Hesham. 2013. "Modelling Energy and Labour Linkages: A CGE Approach with an Application to Iran." Economic Modelling 35:88-98. doi: https://doi.org/10.1016/j.econmod.2013.06.047

Behar, Alberto, and Junghwan Mok. 2013. "Does Public-sector Employment Fully Crowd out Private-sector Employment?" Review of Development Economics 23(4):1891-1925. doi: 10.1111/rode.12613.

Blazquez, Jorge, Lester Hunt, and Baltasar Manzano. 2017. "Oil Subsidies and Renewable Energy in Saudi Arabia: A General Equilibrium Approach." The Energy Journal 38. doi: 10.5547/01956574.38.SI1.jbla.

Chemingui, Mohamed Abdelbasset, and Terry Roe. 2008. "Petroleum Revenues in Gulf Cooperation Council Countries and their Labor Market Paradox." Journal of Policy Modeling 30(3):491-503. doi: https://doi.org/10.1016/j.jpolmod.2007.09.005

Durand-Lasserve, Olivier, Hossa Almutairi, Abdullah Aljarboua, Frederic Murphy, Shreekar Pradhan, and Axel Pierru. 2020. "Sectoral and Economy-Wide Effects of Domestic Energy Price Reforms in Saudi Arabia." KAPSARC Discussion Paper.

Evidence for Policy Design (EPoD). 2015. "Back to Work in a New Economy: Background Paper on the Saudi Labor Market." Harvard Kennedy School, Harvard University.

The Federal Competitiveness and Statistics Authority (FCSA). 2018. Labour Force Survey 2018. Edited by The FCSA.

General Authority for Statistics (GaStat). 2016. GaStat Labour Force Indicators 1999-2016. Riyadh: General Authority of Statistics.
- - - 2019. Statistical Yearbook 2018. Riyadh: General Authority of Statistics.

-- - 2020. Labor Market Bulletin Q4 2019.

Riyadh: General Authority for Statistics.

Gomes, Pedro. 2015. "Optimal Public Sector Wages.” The Economic Journal 125(587):1425-1451. doi: 10.1111/ecoj.12155.

Goyal, Rishi, and Ugo Fasano-Filho. 2004. "Emerging Strains in GCC Labor Markets." IMF Working Papers 04. doi: 10.5089/9781451849271.001.

Gulf Business. 2019. "Expat fees will continue to increase in 2020 as planed - Saudi finance ministry." November 4. https://gulfbusiness.com/ expat-fees-will-continue-increase-2020-plannedsaudi-finance-ministry/

Hertog, Steffen. 2017. "Making Wealth Sharing More Efficient in High-rent Countries: The Citizens' income." Energy Transitions 1(2):7. doi: 10.1007/ s41825-017-0007-2.

- - . 2018. "Can we Saudize the Labor Market Without Damaging the Private Sector?" London School of Economics and Political Science, LSE Library.

International Institute for Strategic Studies (IISS). 2019. The Military Balance 2019. Edited by the IISS. ISBN 9781857439885. Routledge.

International Labour Organization (ILO). 2020a. Labour Migration Statistics. Edited by ILO.

- - - 2020b. Saudi Arabia - Unemployment

Benefit. https://www.ilo.org/dyn/natlex/ natlex4.detail?p_lang=en\&p_isn=99713\&p_ classification $=15.04$ 


\section{References}

- - - 2020c. Statistics on the Working-age Population and Labour Force. Edited by ILO.

Kingdom of Saudi Arabia. 2017. "Vision 2030." https://www.vision2030.gov.sa/sites/default/files/ report/Saudi_Vision2030_EN_2017.pdf

Matar, Walid, Frederic Murphy, Axel Pierru, and Bertrand Rioux. 2015. "Lowering Saudi Arabia's Fuel Consumption and Energy System Costs Without Increasing End Consumer Prices." Energy Economics 49:558-569. doi: 10.1016/j. eneco.2015.03.019.

Merz, Monika. 1995. "Search in the Labor Market and the Real Business Cycle." Journal of Monetary Economics 36 (2):269-300. doi: https://doi. org/10.1016/0304-3932(95)01216-8

Pissarides, Christopher A. 1998. "The Impact of Employment Tax Cuts on Unemployment and Wages; The Role Of Unemployment Benefits And Tax Structure." European Economic Review 42(1):155-183. doi: https://doi.org/10.1016/ S0014-2921(97)00090-1

Peck, Jennifer R. 2017. "Can Hiring Quotas Work? The Effect of the Nitaqat Program on the Saudi Private Sector." American Economic Journal: Economic Policy no. 9 (2):316-47. doi: 10.1257/ pol.20150271.

Saudi Gazette. 2020. " 51,000 citizens register for employment subsidy program.” April 28. https:// www.saudigazette.com.sa/article/592407
Saudi Press Agency. 2020. "With More Than SAR 120 bn: Government of Saudi Arabia Implements Urgent Measures to Mitigate the Impact of Coronavirus on Economic Activities and Private Sector." March 20. https://www.spa.gov.sa/ viewfullstory.php?lang=en\&newsid=2049654

Shehabi, Manal. 2020. "Diversification Effects of Energy Subsidy Reform in Oil Exporters: Illustrations from Kuwait." Energy Policy 138:110966. doi: https:// doi.org/10.1016/j.enpol.2019.110966

Soummane, Salaheddine, Frederic Ghersi, and Julien Lefevre. 2019. "Macroeconomic Pathways of the Saudi Economy: The Challenge of Global Mitigation Action Versus the Opportunity of National Energy Reforms." Energy Policy 130:263-282.

Tamirisa, Natalia, and Christoph Duenwald. 2018. Public Wage Bills in the Middle East and Central Asia. International Monetary Fund 2018.

United Nations Office on Drugs and Crime (UNODC). 2018. Sources for Total Police Personnel at the National Level 2018. Accessed October 2020. https://dataunodc.un.org/data/crime/Police\%20 personnel

World Bank. 2018. The Jobs Agenda for the Gulf Cooperation Council Countries. Washington, DC: The World Bank.

World Bank. 2020. Women, Business and the Law 2020. Washington, DC: International Bank for Reconstruction and Development / The World Bank. 


\section{Appendix A: Expatriate quotas and the shape of the labor demand curve}

Figure A.1. Influence of changes in the foreign worker quota on the labor demand curve.

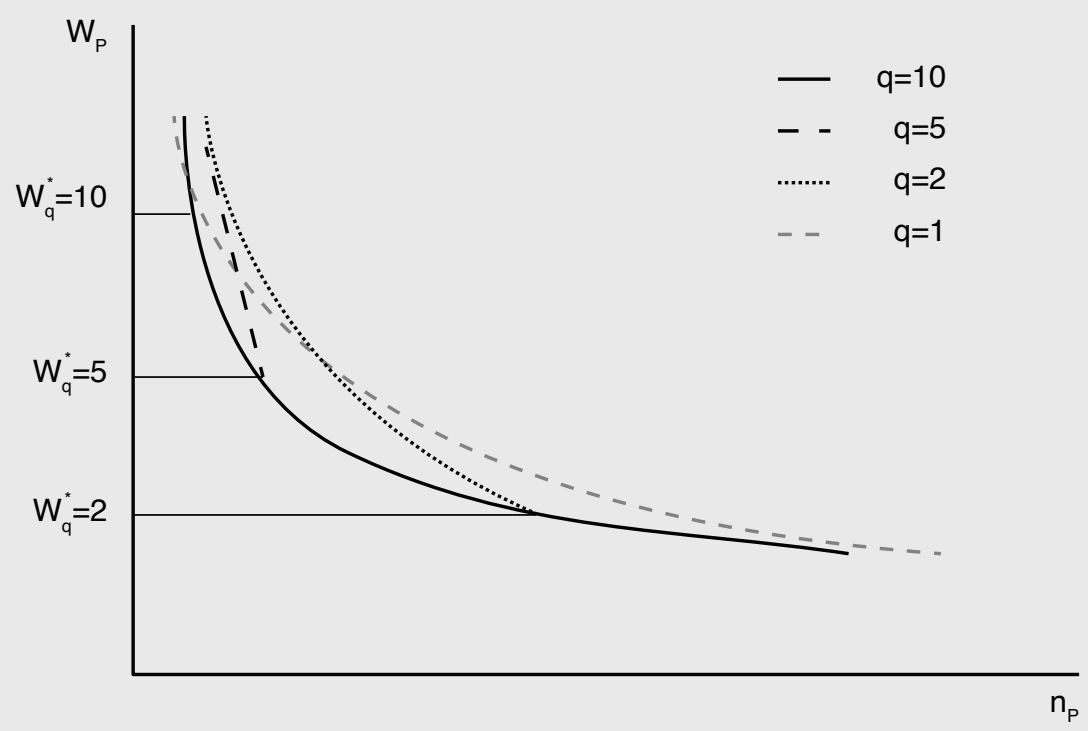




\section{Appendix B: Policy simulations with relaxed expatriate quotas}

Figure B.1. Effects of the quotas, labor subsidies and expatriate levies on unemployment and private sector wages when the quotas are not binding.

Panel A: Effect of the foreign worker quotas
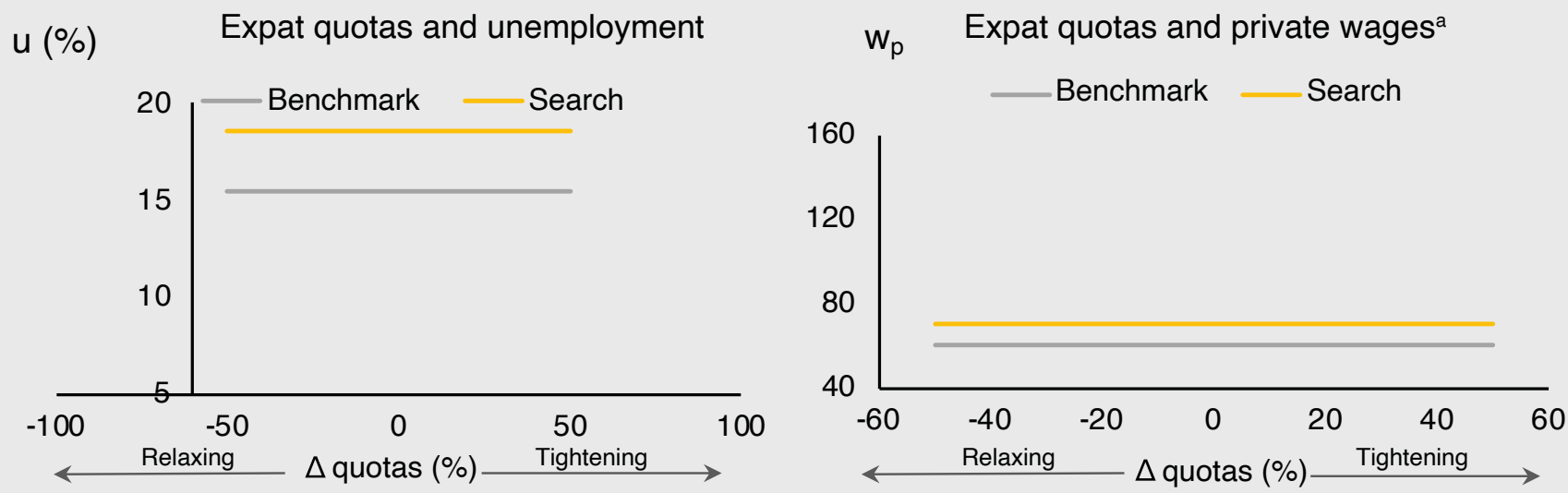

Panel B: Effect of expatriate levies
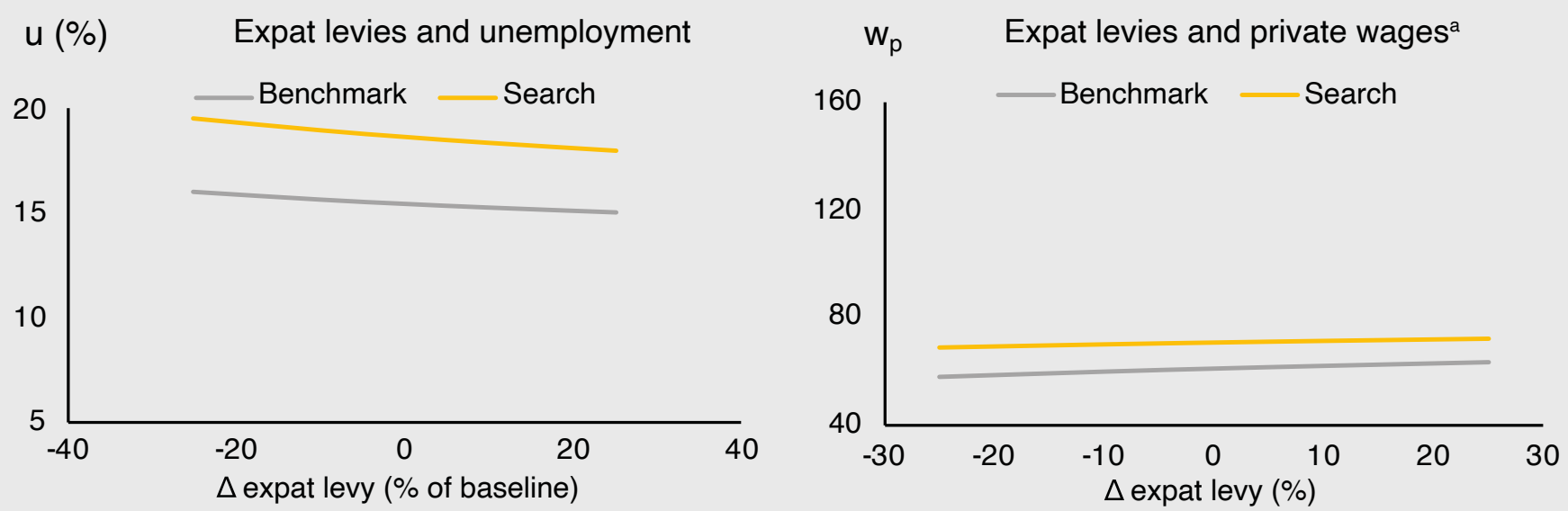

Panel C: Effect of subsidies on national labor
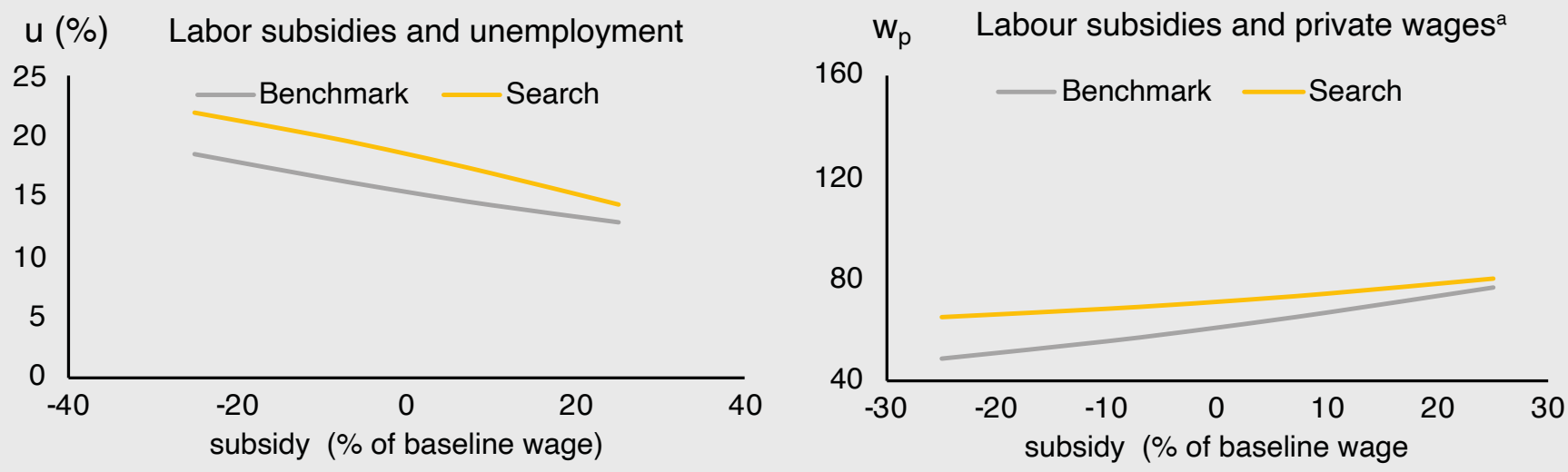

Note: a Nationals' private sector wages are in units of thousand SARs per year. 
Figure B.2. Effects of the replacement ratio and public sector wages and employment on unemployment and private sector wages when the quotas are not binding.

Panel A: Effect of the replacement ratio
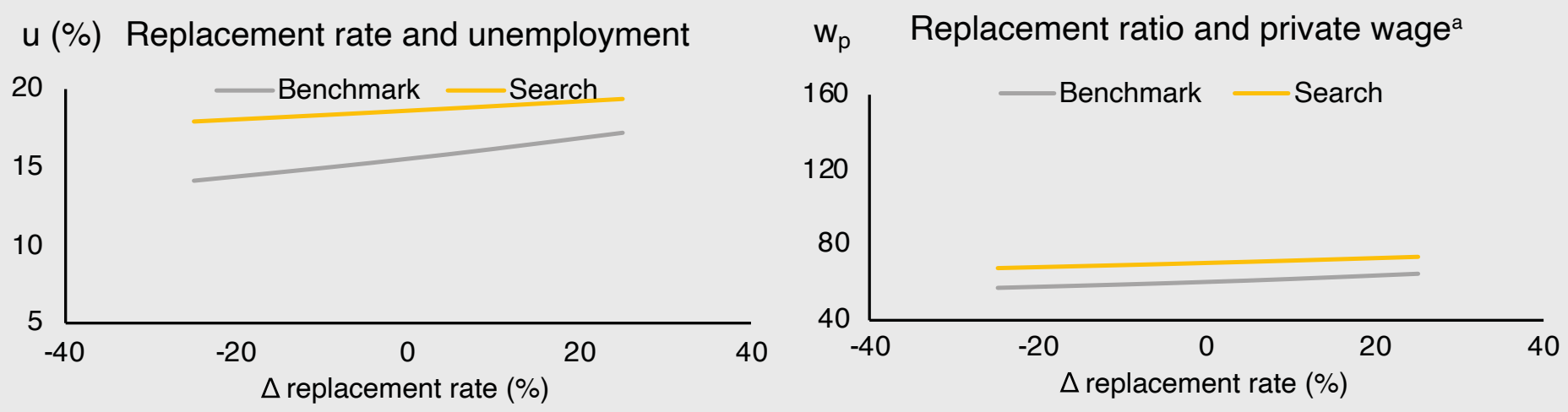

Panel B: Effect of reducing public sector wages
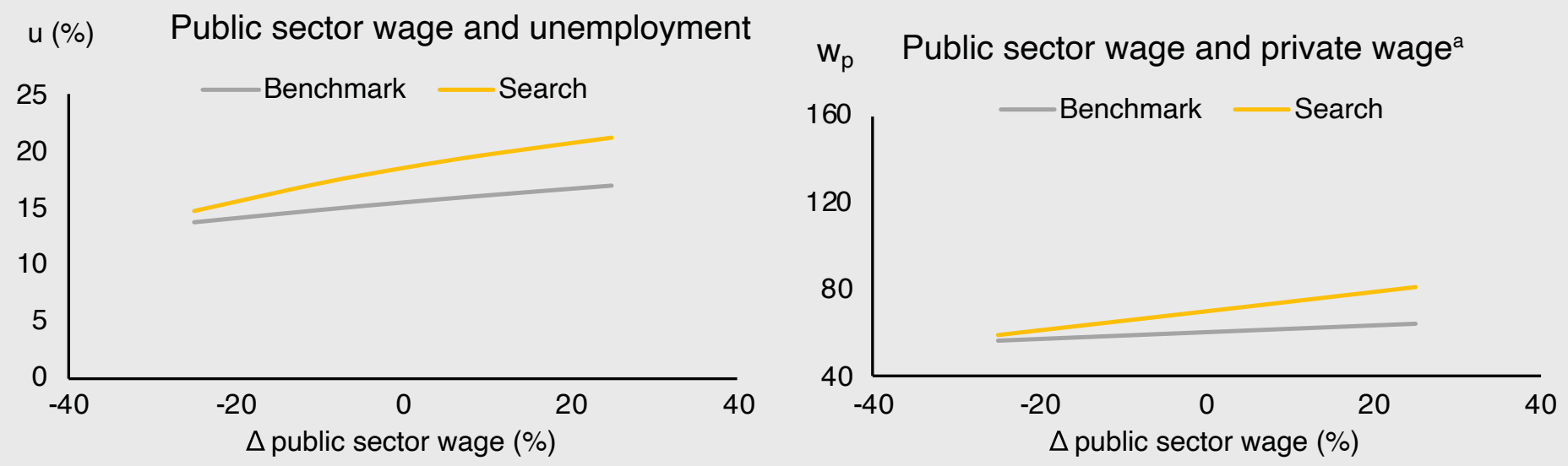

Panel C: Effect of reducing public sector employment

u (\%) Public employment and unemployment

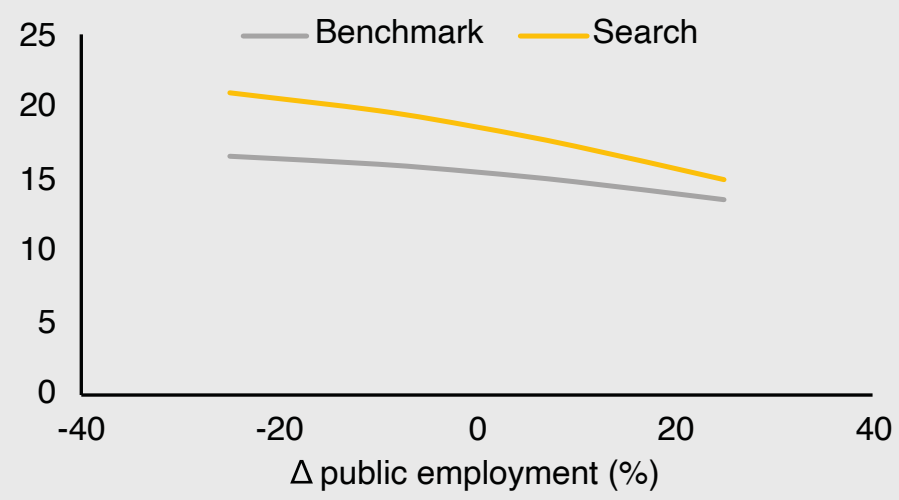

$\mathrm{w}_{\mathrm{p}} \quad$ Public employment and private wage ${ }^{\mathrm{a}}$

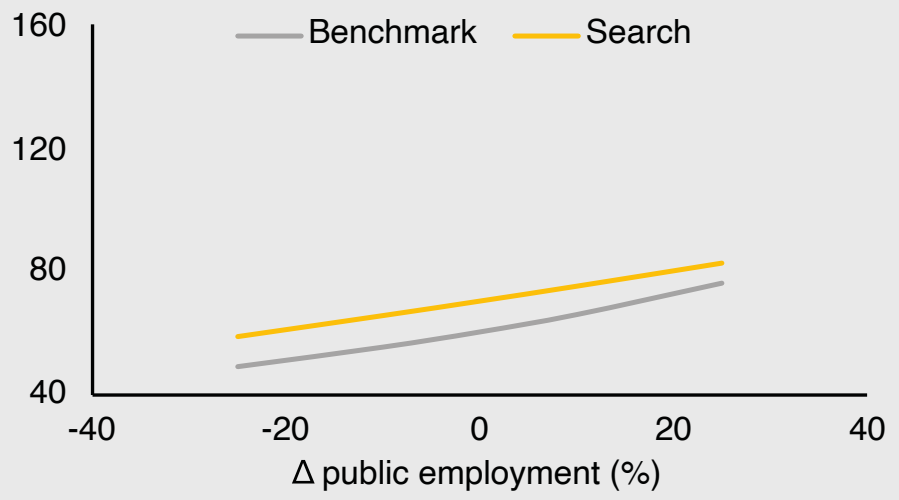

Note: a Nationals' private sector wages are in units of thousand SARs per year. 


\section{Appendix C: National and foreign labor as complements}

Figure C.1. Effects of the quotas, labor subsidies and expatriate levies on unemployment when national and foreign workers are complements $(\xi=0.7)$.

Panel A: Effect of the foreign worker quotas
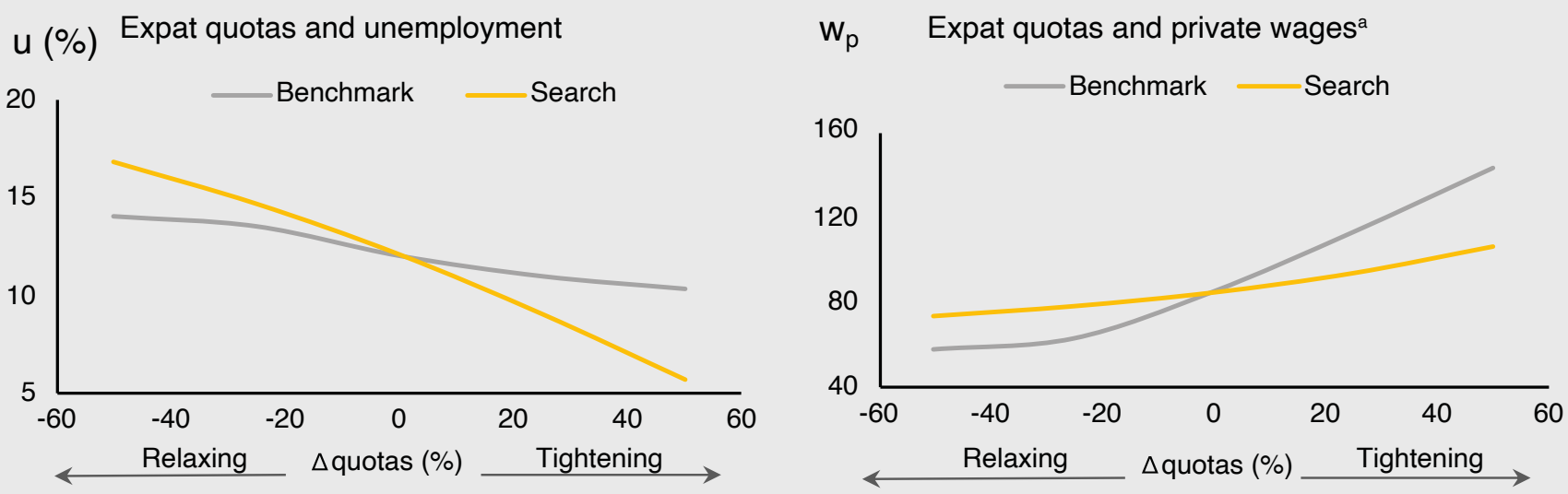

Panel B: Effect of expatriate levies
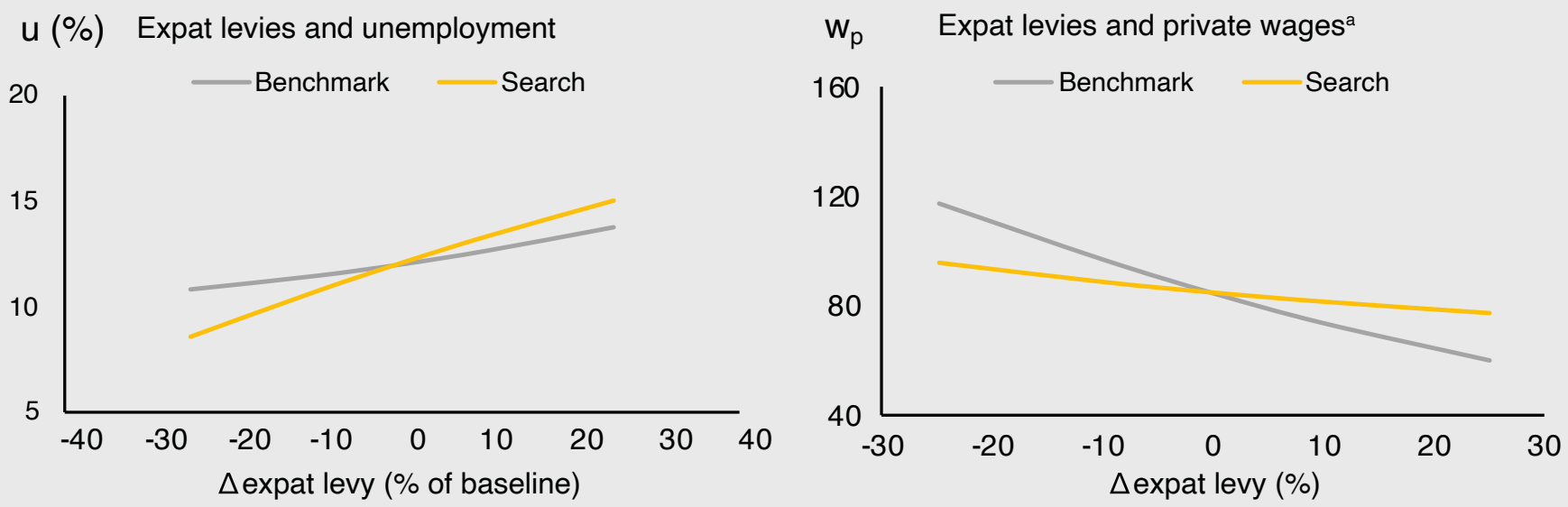

Panel C: Effect of subsidies on national labor
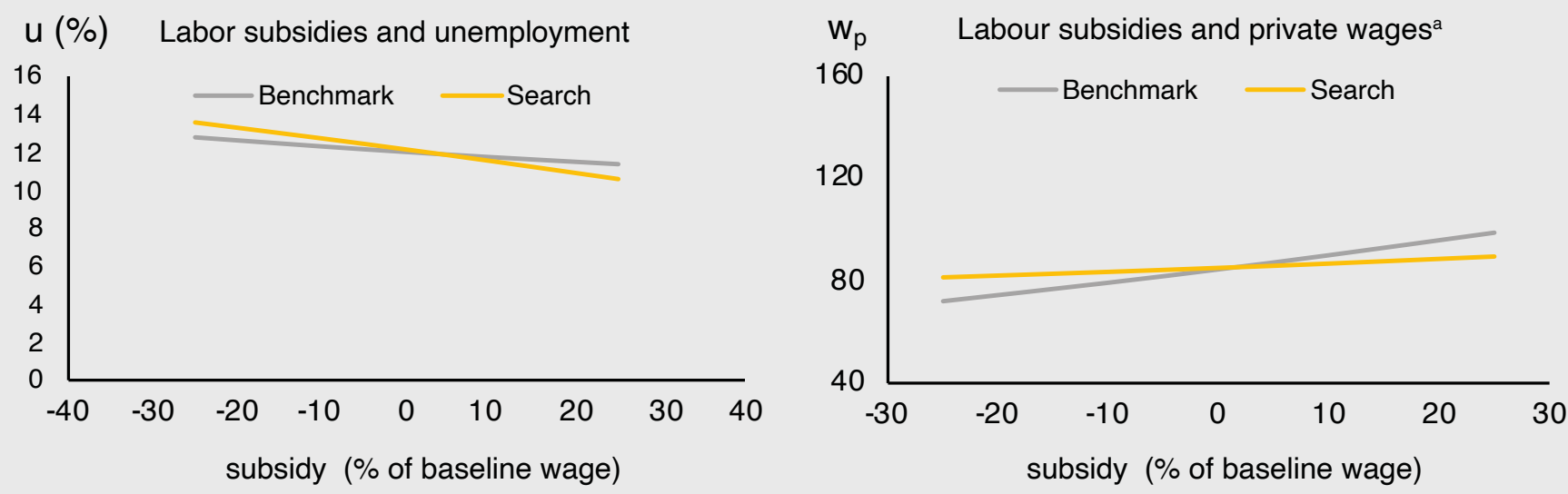

Note: a Nationals' private sector wages are in units of thousand SARs per year. 
Figure C.2. Effects of the replacement ratio and public sector wages and employment on unemployment and private sector wages when national and foreign workers are complements $(\xi=0.7)$.

Panel A: Effect of reducing the replacement ratio
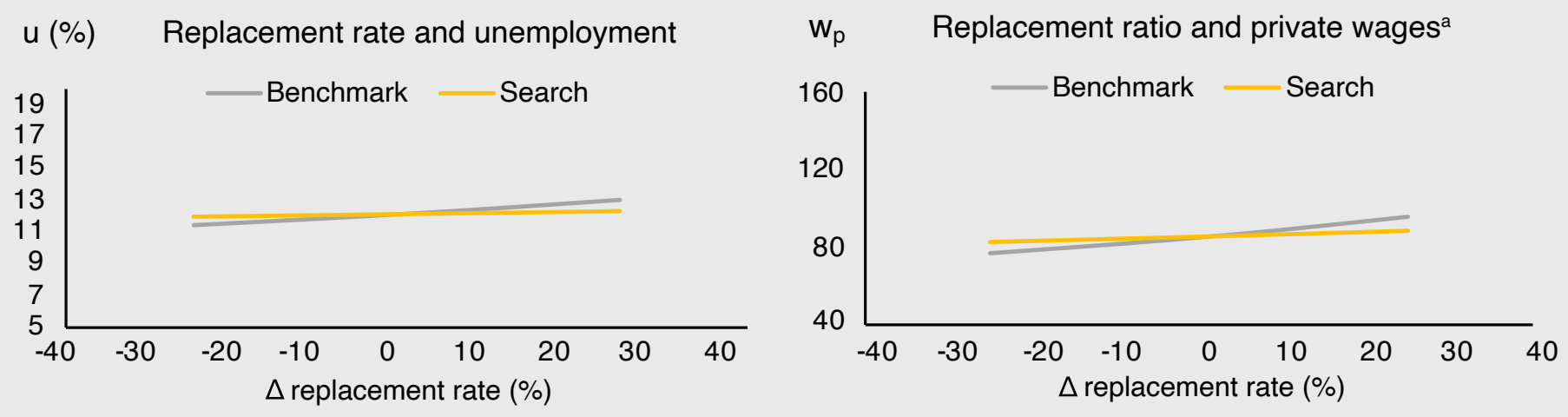

Panel B: Effect of reducing the public sector wage
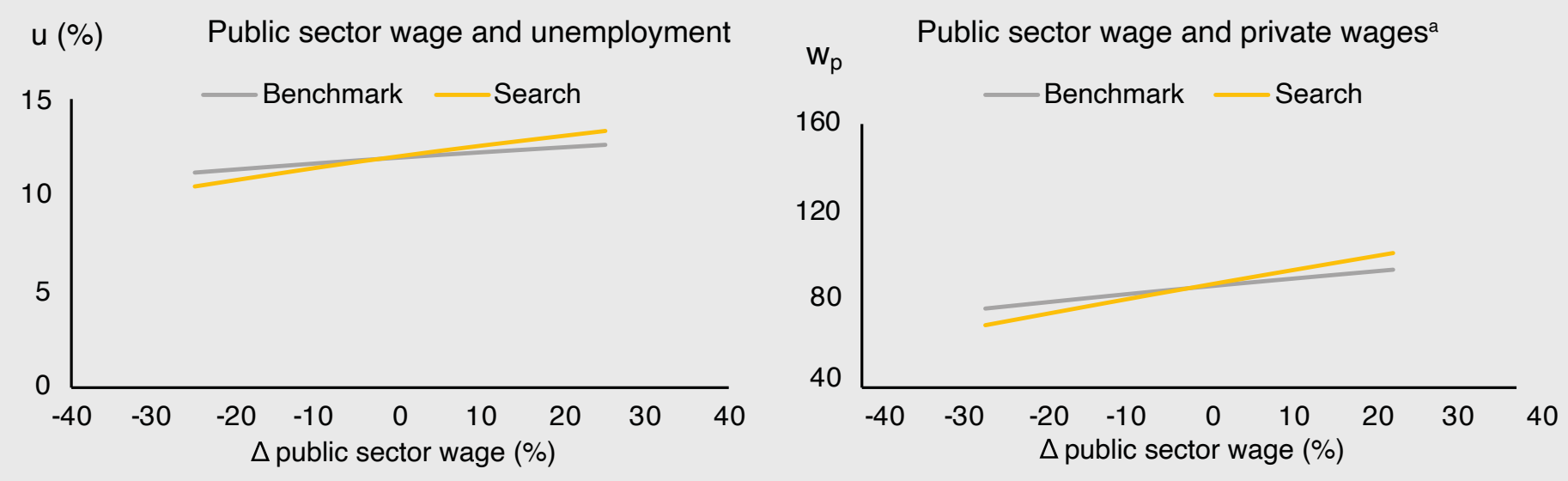

Panel C: Effect of reducing public sector employment
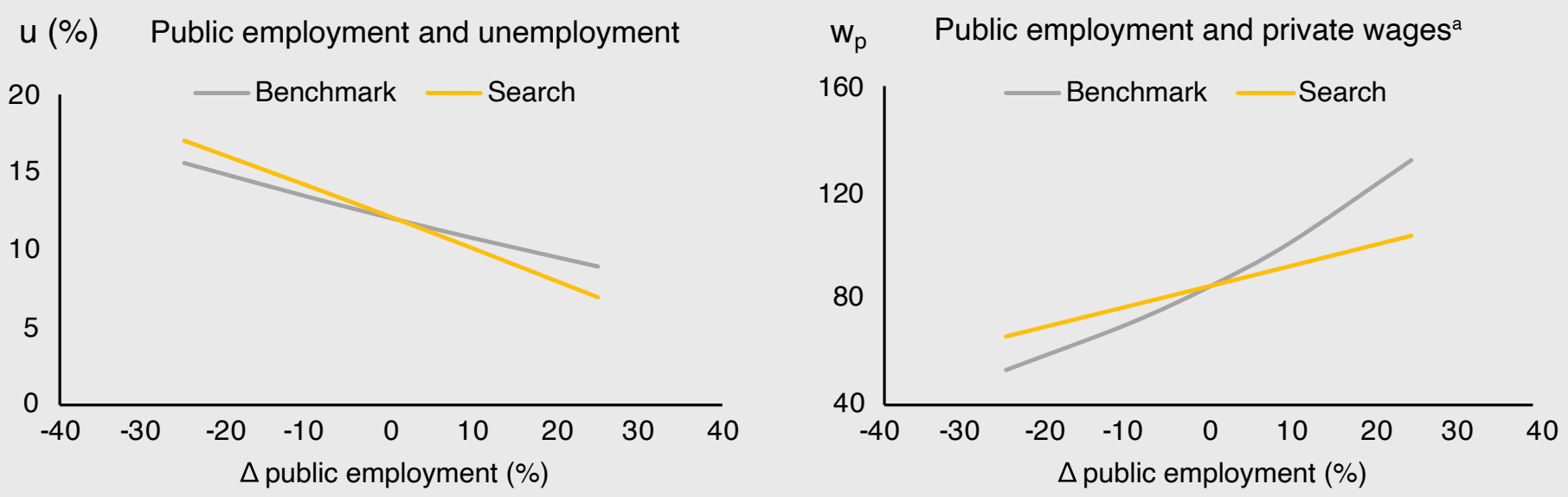

Note: a Nationals' private sector wages are in units of thousand SARs per year. 


\section{Appendix D: Consumption and labor as complements}

Figure D.1. Effects of the quotas, labor subsidies and expatriate levies on unemployment when consumption and labor are complements $(\epsilon=0.8)$.

Panel A: Effect of the foreign worker quotas
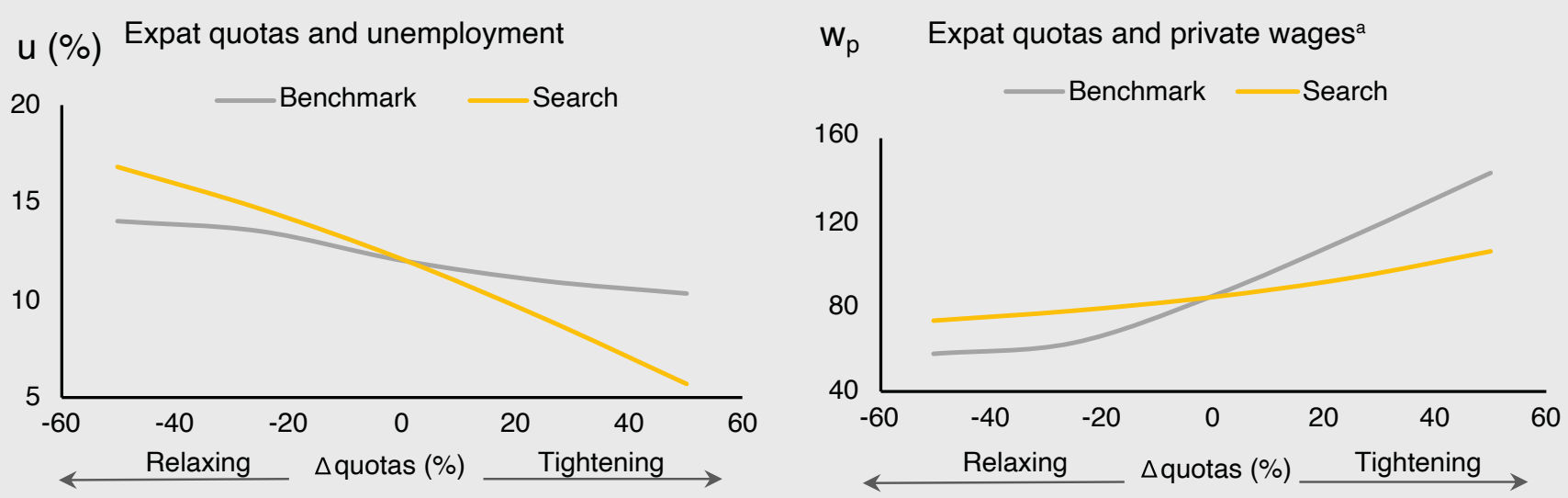

Panel B: Effect of expatriate levies
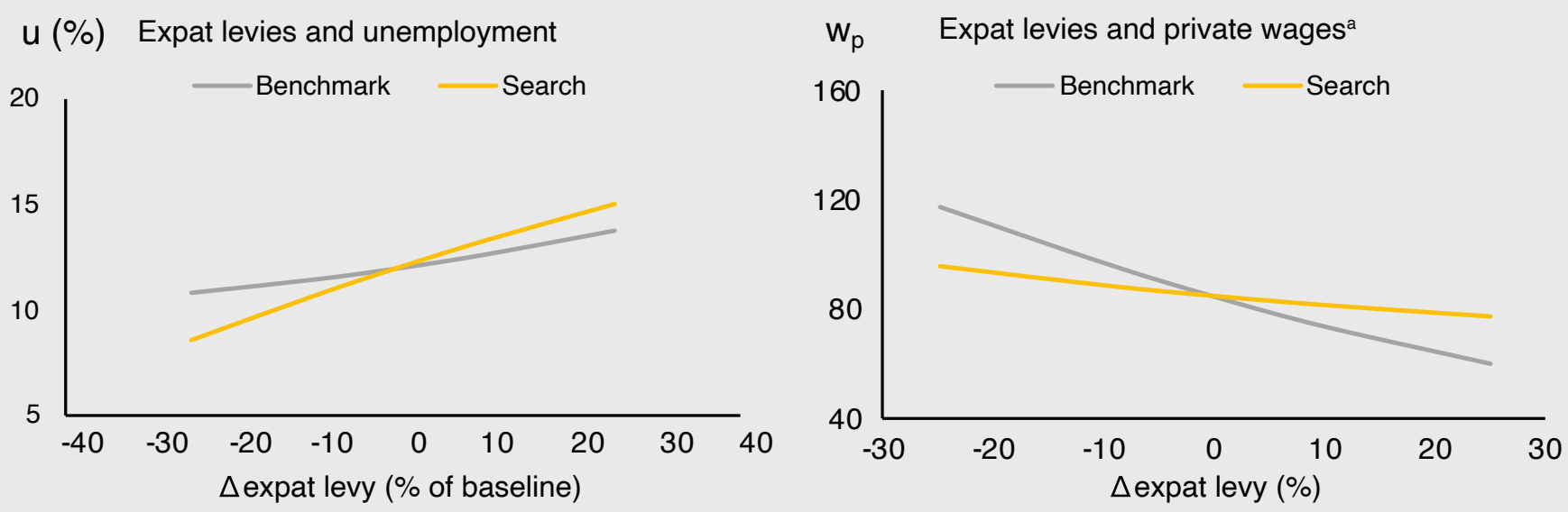

Panel C: Effect of subsidies on national labor
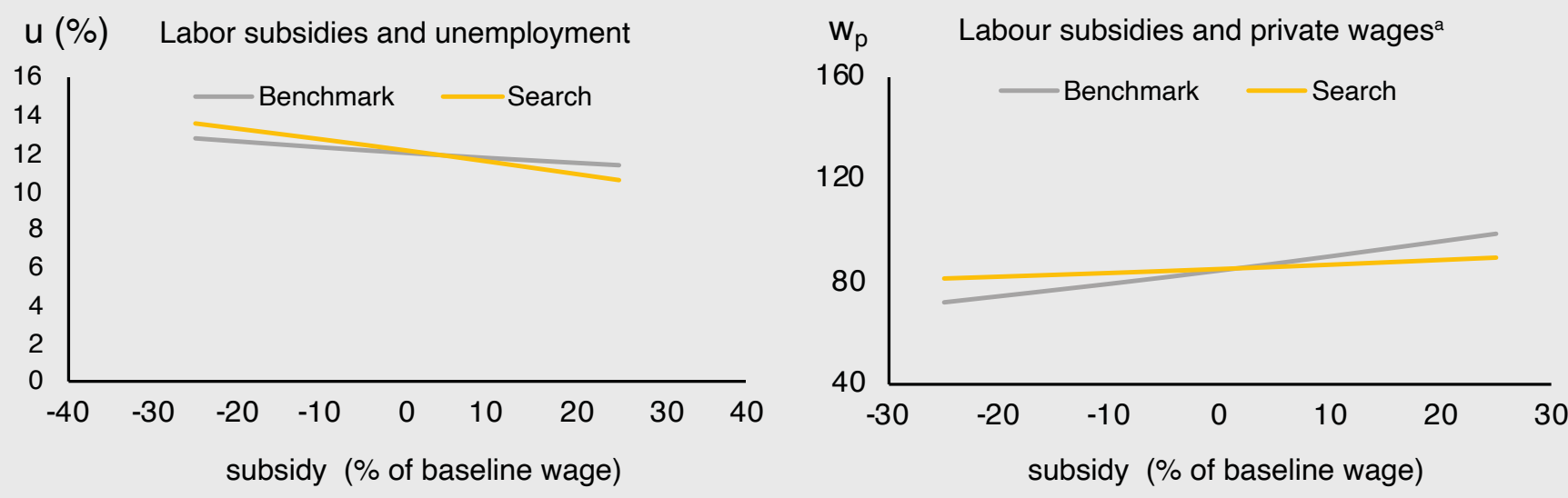

Note: a Nationals' private sector wages are in units of thousand SARs per year. 
Figure D.2. Effects of the replacement ratio and public sector wages and employment on unemployment and private sector wages when consumption and labor are complements $(\epsilon=0.8)$.

Panel A: Effect of reducing the replacement ratio
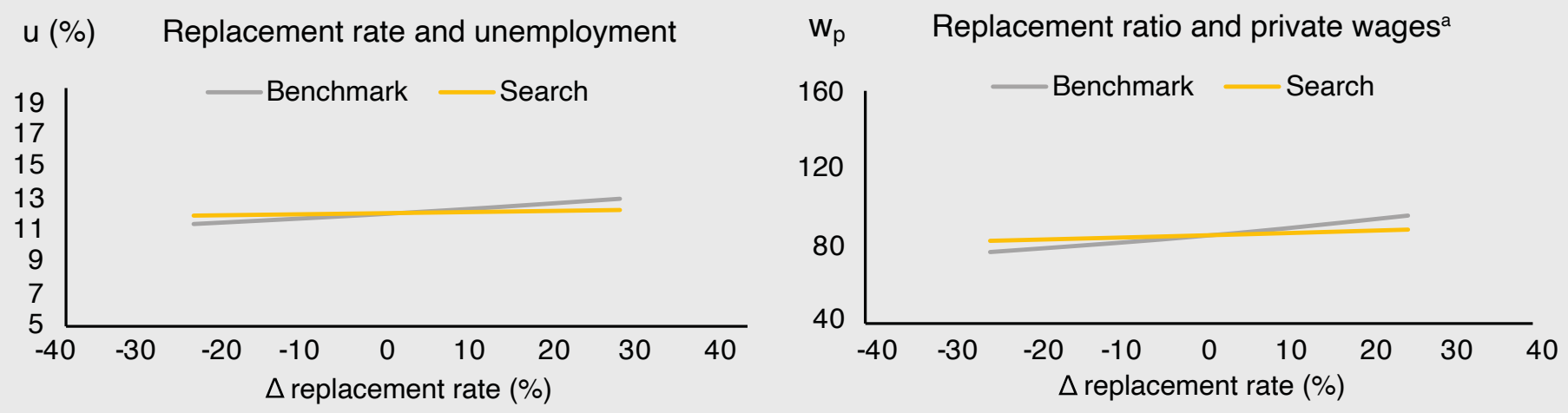

Panel B: Effect of reducing the public sector wage
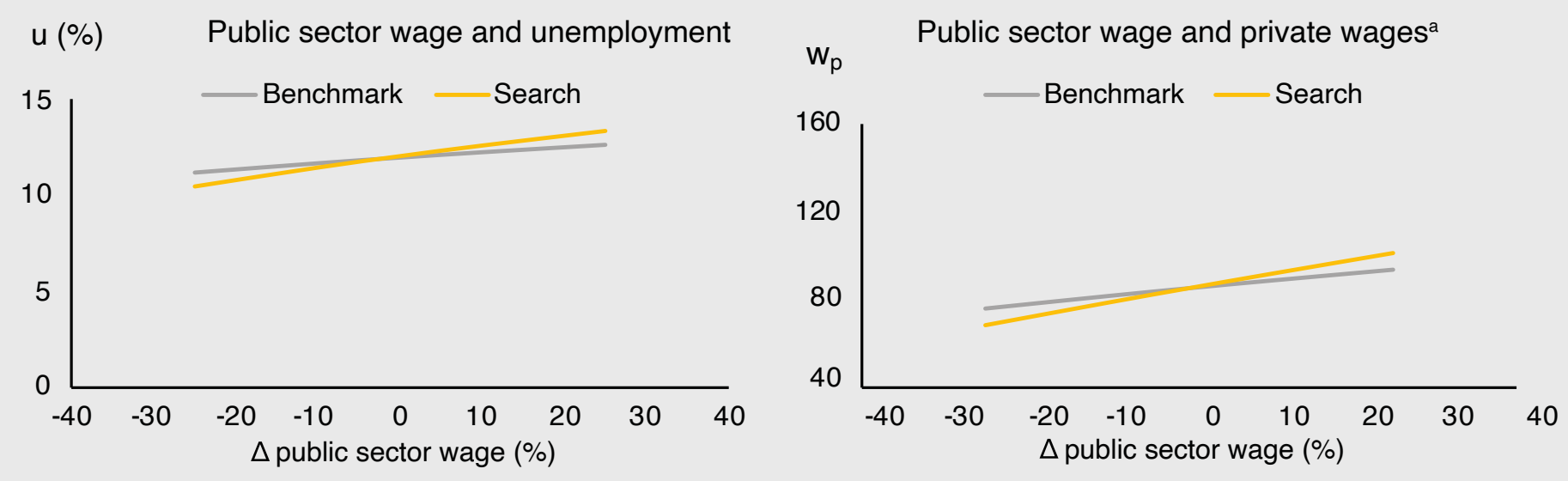

Panel C: Effect of reducing public sector employment
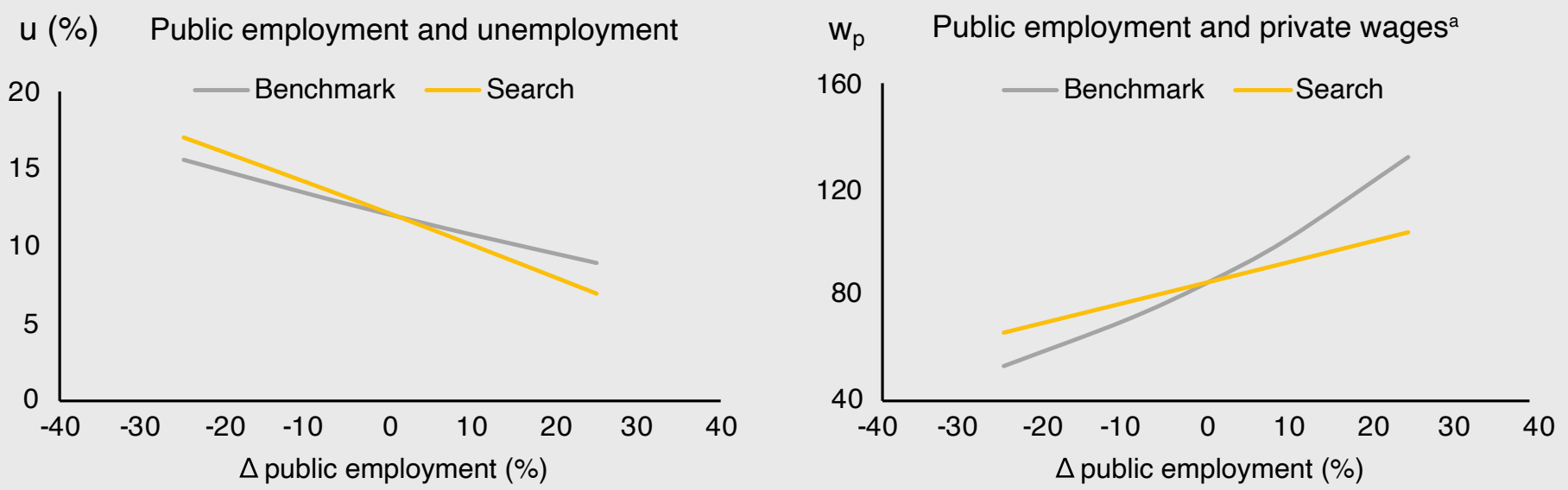

Note: a Nationals' private sector wages are in units of thousand SARs per year. 


\section{Notes}




\section{About the Author}

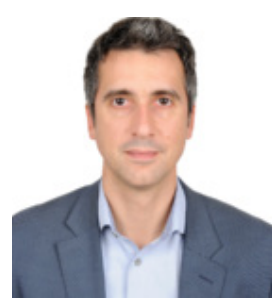

\section{Olivier Durand-Lasserve}

Olivier is a research fellow in the Energy Systems and Macroeconomics program. Previously, he was an economist at the Organisation for Economic Co-operation and Development (OECD) and at the International Energy Agency (IEA) in Paris where his activities covered macroeconomic policy analysis and applied general equilibrium modeling. He contributed to various modeling studies on the assessment of the macroeconomic, environmental and distributional consequences of energy and environmental policies. He also worked on the land-water-energy nexus and on the economic consequences of air pollution. Before he joined the OECD, Olivier worked at ENGIE, in Paris, where he developed an in-house modeling framework for quantifying global long-term energy-economy scenarios. While completing his Ph.D., he was a research assistant at the Center for Operations Research and Econometrics (CORE) in Louvain-la-Neuve, Belgium.

\section{About the Project}

Given the large size of the Saudi energy and energy-intensive sectors, and the structural changes that these sectors will experience over the coming years, it is essential to capture feedbacks between the energy and non-energy components of the economy with sufficient realism.

The KAPSARC Energy Model - General Equilibrium (KEMGE) is a novel hybrid model that combines the KAPSARC Energy Model (KEM) with a representation of the rest of the Saudi economy. It will provide an open-source technology-rich tool to assess the impacts of energy policies on the Saudi economy and the impacts of non-energy policies on the energy sectors. 
INAPSARC

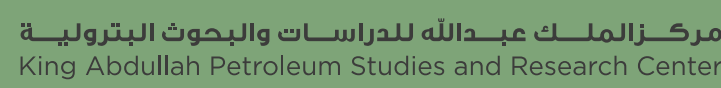

www.kapsarc.org 